\title{
On the nature of dissolved copper ligands in the early buoyant plume of hydrothermal vents
}

\author{
Cotte Laura ${ }^{1,2,{ }^{*}}$, Omanovic Dario ${ }^{3}$, Waeles Mathieu ${ }^{2}$, Laes Agathe ${ }^{4}$, Cathalot Cecile ${ }^{5}$, \\ Sarradin Pierre-Marie ${ }^{1}$, Riso Ricardo D. ${ }^{2}$
}

${ }^{1}$ IFREMER, Lab Environm Profond LEP EEP REM, F-29280 Plouzane, France.

${ }^{2}$ Univ Bretagne Occidentale, Lab Sci Environm Marin LEMAR, F-29280 Plouzane, France.

${ }^{3}$ Rudjer Boskovic Inst, LPCT, Zagreb 10002, Croatia.

4 IFREMER, Lab Detect Capteurs \& Mesures LDCM RDT REM, F-29280 Plouzane, France.

${ }^{5}$ IFREMER, Lab Cycles Geochim \& Ressources LCG GM REM, F-29280 Plouzane, France.

* Corresponding author : Laura Cotte, email address : cottelaura@yahoo.fr

\begin{abstract}
:
Environmental contextCopper released by deep-sea hydrothermal vents has been recognised to be partly stabilised against precipitation by its complexation with strong $\mathrm{Cu}$ binding ligands. Yet, the sources and nature of these compounds in such environments are still not fully understood. This study shows that the Cu ligands detected are hydrothermally sourced and could be mainly inorganic sulfur species. AbstractThe apparent speciation of $\mathrm{Cu}$ in the early buoyant plume of two black smokers (Aisics and Y3) from the hydrothermal vent field Lucky Strike (Mid-Atlantic Ridge) was investigated using competitive ligand exchange-adsorptive cathodic stripping voltammetry (CLE-AdCSV). We have assessed the apparent Cu-binding ligand concentration $([\mathrm{L}])$ and the corresponding conditional stability constant $(\log \mathrm{K})$ for 24 samples. At the smoker Aisics, [L] ranged from 18.2 to 2970nM. Log K-CuL ranged from 12.4 to 13.4. At Y3, the binding capacity of natural ligands was from 32.5 to $1020 \mathrm{nM}$, with Log K-CuL ranging from 12.5 to 13.1. Total dissolved $\mathrm{Cu}$ ranged from 7.0 to $770 \mathrm{nM}$ and from 12.7 to $409 \mathrm{nM}$ at Aisics and $\mathrm{Y} 3$, respectively. Our results show that the amount of ligand $L$ increases with dissolved $\mathrm{Mn}(\mathrm{dMn})$ concentrations, suggesting a hydrothermal origin of the Cu-binding ligands detected. In addition, such high concentrations of Cu-binding ligands can only be explained by an additional abiotic source differing from organic processes. Based on the massive in situ concentrations of free sulfides (up to $300 \mathrm{mu} \mathrm{M}$ ) and on the striking similarities between our log K-CuL and the log K$\mathrm{Cu}(\mathrm{HS})$ previously published, we infer that the Cu-binding ligands could be predominantly inorganic sulfur species in the early buoyant plume of the two vent sites studied.
\end{abstract}




\section{Introduction}

Speciation studies are crucial for understanding the biogeochemical cycle of trace metals in the open ocean. Commonly used to predict the biological availability and the toxicity of metals on microorganisms ${ }^{[1]}$, chemical speciation also brings new insights on which chemical species are controlling the fate of a particular metal in a specific environment.

Hydrothermal fluids are the results of the leaching of oceanic crustal basalts by hot and acidic percolated seawater through the seafloor ${ }^{[2]}$; as a consequence, they are enriched in various inorganic ${ }^{[3]}$ and in small amount of organic species ${ }^{[4,5]}$. The plumes discharging to the deep ocean are a complex mixture of dissolved and particulate species ${ }^{[3,6]}$, mostly reduced, which concentrations depend on the extent of the basalt alteration (i.e. water/rock interactions), as well as the proportion of subsurface mixing with seawater ${ }^{[7]}$. Initial concentrations of species in the plume are also impacted by chemical reactions occurring throughout the mixing of the hydrothermal fluid with seawater.

Despite this complex mixture, previous speciation studies have emphasized the ability of inorganic sulfides to reduce the toxicity of divalent iron ${ }^{[8]}$ or copper ${ }^{[9]}$ by forming metal-sulfide complexes. These previous findings suggest that inorganic sulfides contribute to metalcomplexation in hydrothermal vents. More recently, dissolved copper from deep-sea hydrothermal vents ${ }^{[10,11]}$ and from shallow hydrothermal sources ${ }^{[12]}$ has been recognized to be partly stabilized against precipitation by its complexation with strong organic chelates. These organic ligands, probably thiols ${ }^{[10]}$, have been assumed to compete against inorganic sulfide complexation, hence preventing a part of $\mathrm{Cu}$ from being precipitated across the mixing with seawater. Model simulations have even shown that such organic compounds likely increase the solubility of copper, impacting thus the global $\mathrm{Cu}$-fluxes in the ocean ${ }^{[13]}$. Specific organic ligands for iron have also been detected in hydrothermal buoyant plumes ${ }^{[14-16]}$, suggesting a stabilization in the dissolved phase as well as a higher solubility of iron in the deep ocean. 
However, the source and nature of these organic compounds in such environments are still poorly known. Organosulfur compounds coming from biologically-rich diffuse areas, rather than typical oceanic ligands (e.g. humic substances ${ }^{[17]}$ ) have been suggested to be the main organic species found in such environment and thus to represent these organic ligands ${ }^{[10-12]}$. Despite these assumptions, the potential impact of reduced sulfur species on metal speciation is still pointed out ${ }^{[11,12]}$. Because of their massive concentrations in the hydrothermal endmembers (from $\mu \mathrm{M}$ to $\mathrm{mM}$ levels) ${ }^{[1,15]}$, inorganic sulfides should indeed play an important role in metal-complexation in the early buoyant plume.

In this study we provide new data on the apparent speciation of $\mathrm{Cu}$ in the early buoyant plume of two black smokers located in the Lucky Strike hydrothermal vent field (Mid-Atlantic Ridge).

We discuss the apparent ligand concentrations obtained in line with DOC levels and, for the first time, with the in situ measurements of total inorganic sulfides in the buoyant plume. We then anticipate on what is the nature of the copper binding ligands in the studied area in line with the corresponding in situ parameters measured.

\section{Experimental}

\subsection{Sampling sites}

Hydrothermal fluid samples were collected at the Lucky Strike vent field $\left(37^{\circ} \mathrm{N}\right)$ during two oceanographic cruises on the RV Pourquoi Pas? and the Atalante (Momarsat 2015: http:// dx.doi.org/10.17600/15000200 and Momarsat 2016: $\underline{\text { http://dx.doi.org/10.17600/16001200). }}$

The Lucky Strike Seamount is located southwest of the Azores Islands on the slow-spreading Mid-Atlantic ridge $(\mathrm{MAR})\left(\sim 2.2 \mathrm{~cm} / \mathrm{yr}^{[18,19]}\right)$ and extends over almost $11 \mathrm{~km}$ at depth between 1800 and $2000 \mathrm{~m}^{[20]}$. The volcano summit is made of three volcanic cones surrounding a flat depression which hosts a fossil lava lake as well as the Lucky Strike vent field (average depth: 
$1690 \mathrm{~m})$. Hydrothermal activity is gathered around the lava lake which prevents hydrothermal fluids from directly discharging through the crust ${ }^{[20-22]}$. The Lucky Strike vent field displays a wide variety of emission and structures which are all hosted on a basaltic substratum ${ }^{[23]}$. Two black smokers from Lucky Strike were selected to study the nature of the $\mathrm{Cu}$-binding ligands: Aisics $\left(32^{\circ} 17.34^{\prime} \mathrm{N} ; 32^{\circ} 16.53^{\prime} \mathrm{W}, 1690 \mathrm{~m}\right.$ depth) and $\mathrm{Y} 3\left(37^{\circ} 17.51^{\prime} \mathrm{N} ; 32^{\circ} 16.67^{\prime} \mathrm{W}, 1726 \mathrm{~m}\right.$ depth) (Figure 1). 8

\subsection{Sampling method}

At each site, in-situ filtration was carried out in the early buoyant plume of each smoker using the PEPITO sampler ${ }^{[24]}$ implemented on the ROV Victor 6000 (Figure 1). Prior to use, all equipment used for sampling and filtration was rigorously washed with diluted hydrochloric acid ( $\mathrm{pH}$ 2, Suprapur, Merck) and rinsed with ultrapure water (Milli-Q element system). The in-situ filtered samples were collected by pumping water into 2L-PVC/DEHP blood bags (Terumo, sterile treated by ethylene oxide, PVC/DEHP, 1BDT200BM) with on-line filtration at $0.45 \mu \mathrm{m}$ (HATF, Millipore). For each dive, sampling was performed towards increasing temperatures, i.e. from the seawater-dominated to the hydrothermal-dominated part of the mixing zone, thus minimizing potential contamination of the sampler. The acid-cleaned titanium-silicone nozzle of the sampling device was first positioned in the buoyant plume, at 1 to $2 \mathrm{~m}$ from the vent orifice. A high-temperature probe coupled to the nozzle was used to monitor the temperature at each point of the mixing gradient sampled. When the temperature probe was stabilized at $4^{\circ} \mathrm{C}$ (coldest part of the mixing), the pumping of the first sample (A1) was started and held for 3 to $5 \mathrm{~min}$. The nozzle was then shifted downwards within the central part of the buoyant plume with temperature increments of $\sim 10^{\circ} \mathrm{C}$ until reaching values ranging from 100 to $150^{\circ} \mathrm{C}$. Overall, 15 samples were collected for each of the 2 mixing gradients sampled. Pumping was systematically stopped in case of a steep increase in temperature (e.g. 
$10010^{\circ} \mathrm{C}$ to $100^{\circ} \mathrm{C}$ in a few seconds) or a chimney structure collapsing to avoid samples

101 contamination by particles.

102 Coupled to the PEPITO sampling, one chemical miniaturized analyzer (CHEMINI ${ }^{[25]}$ ) was

103 used for the in situ measurement of sulfides $\left(\Sigma \mathrm{S}=\mathrm{HS}^{-}+\mathrm{S}^{2-}+\mathrm{H}_{2} \mathrm{~S}\right)^{[26]}$. Briefly, $\Sigma \mathrm{S}$ measurement

104 is based on flow injection analysis with colorimetric detection (methylene blue method). The

105 chemical analyzer was calibrated in situ at the beginning and at the end of each dive using S(-

106 II) stock solutions. Hydrothermal solutions were directly pumped without any filtration and the

107 signal acquisition ( $~ 3 \mathrm{~min})$ was initiated at the same time as the PEPITO sampling (the same

108 titanium-Silicon cannula is used for both PEPITO and CHEMINI). The chemical species

109 analyzed corresponded to an operationally defined fraction of sulfides, herein called free

110 sulfides. This fraction included the dissolved and particulate sulfides in unfiltered seawater that

111 are labile enough to react with methylene blue at $\mathrm{pH} 4.7$ (acetate buffer). In situ measurement

112 of dissolved oxygen was performed using an optode (Aanderaa).

113 Immediately after recovery of the ROV, samples were processed in the chemical lab on board

114 (clean lab, Class 100 000, ISO 8) and pH was measured on dedicated aliquots using a daily-

115 calibrated $\mathrm{pH}$-meter (NBS buffers: $\mathrm{pH} 4,7$ and 10 at $25^{\circ} \mathrm{C}$ ). Each bag was then sub-sampled

116 for further spectrometric analysis of the total dissolved concentrations of dissolved manganese

$117(\mathrm{dMn})$. Aliquots were stored in acid-cleaned $15 \mathrm{~mL}$-polypropylene tubes (Elkay) and

118 immediately frozen at $-4^{\circ} \mathrm{C}$ until on shore analysis. The remaining volume in the PVC/DEHP-

119 bags was dedicated to $\mathrm{Cu}$-speciation measurements.

\subsection{Storage strategy and analyses performed for the assessment of $\mathrm{Cu}$ speciation}

121 The protocol used for storage and on-shore analyses for the assessment of $\mathrm{Cu}$ speciation is

122 summarized in Figure 2. In total, thirty hydrothermal samples were dedicated to the study of

123 Cu-binding ligands. Samples collected in 2015 were poisoned directly inside the PVC/DEHP-

124 bag with sodium azide $\left(\mathrm{NaN}_{3}\right.$, extra pure, Merck) and stored at $4{ }^{\circ} \mathrm{C}$ for one year. For $500 \mathrm{~mL}$ 
frozen and poisoned samples were available in 2015, with the aim at comparing the effect of

freezing at $-20^{\circ} \mathrm{C}$ was reported to modify the original speciation of $\mathrm{Cu}$, suggesting that this storage was not fully adapted for such measurements compared to a storage at $4^{\circ} \mathrm{C}^{[27]}$.

discussed cautiously. Samples from the second cruise (2016) were immediately transferred in $500 \mathrm{~mL}$ PFA bottles after recovery on board and also poisoned with azide before storage at $4{ }^{\circ} \mathrm{C}$ for 2 months. Aliquots from bags and bottles were then analyzed on shore by High Resolution Inductively Coupled Plasma Mass Spectrometry (HR ICP-MS) for total dissolved copper (dCu) concentrations (see paragraph 2.5).

Reduced Sulfide Species (RSS) concentrations appeared to be so high in 2016 that a

140 pretreatment of samples was needed to enable any electrochemical measurement of labile $\mathrm{Cu}$.

141 Prior to the complexometric titration experiments, samples were purged with clean air for about

$1421.5 \mathrm{~h}$ to remove volatile sulfides. They were left to equilibrate overnight and then filtered at $1430.2 \mu \mathrm{m}$. Samples were not acidified before purging to minimize the chemical changes of the 144 natural inorganic and organic ligands. We also tested the procedure which involves acidification 145 of sample and purging with $\mathrm{N}_{2}$, as described by Sander et al. ${ }^{[10]}$, but we did not observe any 146 improvement in the voltammogram shape when compared to the 'air purging' method we 147 applied. The clean air purging led to the oxidization of some inorganic $\mathrm{RSS}$ as $\mathrm{SO}_{4}{ }^{2-}$ but also 148 as $\mathrm{S}^{0}$ or polysulfides particles that probably trapped some dissolved $\mathrm{Cu}$. To ensure a correct 149 measurement of the remaining dissolved $\mathrm{Cu}$, pretreated samples were re-analyzed by ASV as 
150 described in section 2.4.2.d. The final $\mathrm{Cu}$ concentrations obtained for pretreated samples are

151 labelled $\mathrm{dCu}^{*}$ and are used for calculations of $\mathrm{L}^{*}$ concentrations and of $\log \mathrm{K}^{*} \mathrm{CuL} . \mathrm{L}^{*}$ and

$152 \log \mathrm{K}^{*} \mathrm{CuL}$ will thus represent the complexing parameters for $\mathrm{Cu}$-binding ligand resistant to

153 oxidation processes. The pre-treatment was not required for samples from 2015 because of the

154 lower apparent RSS concentrations. Dissolved copper concentrations $(\mathrm{dCu})$ obtained by $\mathrm{HR}$

155 ICP-MS were used for calculations of $\mathrm{L}$ and $\log \mathrm{K}_{\mathrm{CuL}}{ }_{\mathrm{CuL}}$. For voltammetric titration experiments,

156 untreated samples refer to samples collected at Y3 and Aisics in 2015.

157 Because samples collected in 2016 were treated differently than those collected in 2015, the

158 two datasets could not be directly compared. Despite this important issue, each dataset enabled

159 to shed different insights on the speciation of $\mathrm{Cu}$ in hydrothermal vents and was thus used

160 accordingly. On one hand, samples from 2015, which remained untreated, were the most

161 comparable to the other $\mathrm{Cu}$ speciation data that have been previously published. This dataset

162 was also the most reflective of relatively unperturbed $\mathrm{Cu}$ speciation, bearing in mind that any

163 hydrothermal sample is perturbed during storage or $\mathrm{pH}$ buffering. On the other hand, samples

164 from 2016 enabled to discuss on the relative importance of organic ligands relative to inorganic

165 ligands.

166

167

\subsection{Voltammetric measurements}

\subsubsection{Analytical equipment and reagents}

169 Voltammetric measurements were performed using the potentiostat-galvanostats

170 PGSTAT128N or $\mu$ Autolab III (Metrohm) controlled by GPES 4.9 software coupled with a

171 three-electrode system 663 VA stand (Metrohm) at the Ruđer Bošković Institute (RBI),

172 Croatia. The working electrode was a Hanging Mercury Drop Electrode (HDME) (drop area:

$1730.25 \mathrm{~mm}^{2}$ ). A double junction $\mathrm{Ag} / \mathrm{AgCl} / \mathrm{sat}$. $\mathrm{NaCl} / \mathrm{UVSW}$ and a platinum wire were used as the

174 reference and the counter electrodes, respectively. UVSW used for experiments refers to UV- 
175 irradiated seawater collected off-shore of Šibenik (Croatia). Solutions were stirred during the

176 deposition step by a quartz or a Teflon stirrer rotating at $3000 \mathrm{rpm}$. Experiments were conducted

177 in a quartz cell with a working volume of $10 \mathrm{~mL}$. All measurements were carried out at room

178 temperature $\left(\sim 25^{\circ} \mathrm{C}\right)$. $\mathrm{pH}$ was monitored using a pH-meter (Orion Research, model 920 ) with a

179 daily calibrated pH electrode (Metrohm). Ultra clean water (ASTM Type I, 18.2 M 2 ; Milli-Q)

180 used for final washings and preparation of chemicals was purified by combining Elix 5 and

181 Synthesis 10 purification systems from Millipore. All sample containers were acid-cleaned with

$18210 \%$ nitric acid $\left(\mathrm{HNO}_{3} 65 \%\right.$, analytical reagent grade) and thoroughly rinsed with Milli-Q water

183 before use. Only fluorinated ethylene propylene (FEP) or perfluoroalkoxy (PFA) bottles were

184 used. Prior to voltammetric measurement, an aqueous stock solution containing $0.05 \mathrm{M}$

185 salicylaldoxime (SA, 98\% Sigma) was prepared and stored at $4^{\circ} \mathrm{C}$. A $1 \mathrm{mM} \mathrm{SA}$ standard was

186 then prepared from the $0.05 \mathrm{M}$ stock solution and used for voltammetric analyses. A pH buffer

187 was made by dissolution of boric acid (Suprapur, Merck) in $0.35 \mathrm{M}$ ammonia (>25\%,

188 TraceSelect, Fluka) to obtain a $1 \mathrm{M}$ solution. The addition of $100 \mu \mathrm{L}$ of this buffer in $10 \mathrm{~mL}$

189 sample gave a $\mathrm{pH}$ of 8.2 in the cell. Slightly acidic $\mathrm{Cu}$ standards solutions $\left(10^{-6} ; 10^{-5}\right.$ and $10^{-}$

$\left.190{ }^{4} \mathrm{M}\right)$ were prepared in Milli-Q water $(\mathrm{pH} \sim 3)$ from a $1 \mathrm{~g} \cdot \mathrm{L}^{-1} \mathrm{Cu}$-stock solution (Fluka).

191

\subsubsection{Determination of Cu complexing parameters by CLE-AdCSV}

\subsection{2.a Titration procedure}

194 The $\mathrm{Cu}$ binding ligands concentration ([L] or $\left.\left[\mathrm{L}^{*}\right]\right)$ and the corresponding conditional stability

195 constant $\left(\log \mathrm{K}^{\prime}\right.$ or $\left.\log \mathrm{K}^{*}\right)$ were assessed using Competitive Ligand Exchange - Adsorptive

196 Cathodic Stripping Voltammetry (CLE-AdCSV) with SA as the competing ligand [28].

197 Theoretical background as well as details for the calculation of complexation parameters are

198 provided in supplementary information. In order to perform CLE-AdCSV experiments within 
199 the linear range of the method (up to $\sim 400 \mathrm{nM}$ of $\mathrm{Cu}_{\mathrm{T}}$ ), untreated samples with high $\mathrm{Cu}$ content 200 ( $1^{\text {st }}$ set) were generally diluted 10 -fold in clean UVSW $(\mathrm{dCu}<1 \mathrm{nM})$. Pretreated samples $\left(2^{\text {nd }}\right.$ 201 set) were not diluted as the signal measured without addition of $\mathrm{Cu}$ was generally low.

202 Preparations for titration experiments were carried out under a laminar flow hood in a $500 \mathrm{~mL}-$ 203 acid-cleaned FEP bottle and in fifteen 30-mL acid-cleaned FEP flasks with ETFE screw caps. 204 A $16^{\text {th }} 30-\mathrm{mL}$ flask was used for the blank. The analysis was carried out using an automated system equipped with an in-house made sample changer which allowed the addition of the sample in the cell plus a rinse between each aliquot. A volume of $20 \mathrm{~mL}$ was needed in each of the 15 flasks (i.e. $10 \mathrm{~mL}$ for the rinse and $10 \mathrm{~mL}$ for the analysis). When 10 -fold diluted, $30 \mathrm{~mL}$ of sample was first transferred in the 500-mL FEP bottle. Then, borate buffer and SA were added in order to reach a $\mathrm{pH}$ of $8.2 \pm 0.2$ and a SA concentration of $4 \mu \mathrm{M}$ in final solution.

210 UVSW was finally added to achieve the total volume of $300 \mathrm{~mL} .20 \mathrm{~mL}$ aliquots of the solution 211 were then pipetted into the 15 FEP flasks. $\mathrm{Cu}$ was added to each flask in logarithmic steps ${ }^{\text {[29] }}$ 212 progressively increasing the additions from 0 to $300 \mathrm{nM}$ by using automatic burette system 213 (XE1000, TECAN). The blank consisted of UVSW prepared directly in the 30-mL flask with $2140.01 \mathrm{M}$ borate buffer and $4 \mu \mathrm{M}$ of SA. The 16 flasks were left to equilibrate overnight at room 215 temperature ( $8 \mathrm{~h}$ minimum). Concentration of labile $\mathrm{Cu}$ was then determined by $\mathrm{CSV}$ using 21630 to $180 \mathrm{~s}$ deposition time. The deposition potential was $-0.1 \mathrm{~V}$ followed by a $5 \mathrm{~s}$ equilibration 217 time and a cathodic scan from $0.05 \mathrm{~V}$ to $-1.6 \mathrm{~V}$ using the square wave (SW) mode (step potential $2182 \mathrm{mV}$, frequency $50 \mathrm{~Hz}$ ). Five repetitions for each aliquot were made for quality control. 219 Overall, precision was better than $2 \%$. The titration experiment performed in UVSW showed 220 fully linear response, confirming that the chosen titration range was adequate.

221 Once the voltammogram treatment was performed (see 2.4.2.c), final titration curves were plotted in the ProMCC software. Conditional stability constant as well as ligand concentrations 223 were modelled using the complete complexation-fitting model ${ }^{[30]}$. For all samples, the use of 
2241 ligand model gave proper estimations of both conditional stability constant and $\mathrm{Cu}$-binding 225 ligands concentrations.

\subsection{2.b Side reaction coefficient}

227 Most of samples were diluted in UVSW of salinity 38 resulting in a final salinity of around 3522836 in the measured samples. As salinity and the SRC of CuSA were close among samples, 229 calculations of stability constants for diluted samples were all conducted with a salinity value 230 of 36 . Values of 9.54 and 14.96 for $\log K_{C u S A}^{\prime}$ and $\log \beta_{C u(S A) 2}^{\prime}$ were obtained and used for all 231 further calculations. A value of 13 was chosen for inorganic side reaction coefficient $\alpha_{X}$ and 232 used in calculations ${ }^{[31]}$.

\subsection{2.c Signal treatment and final titration curves}

234 All voltammograms treatment was performed using the software ECDSOFT available at

235 https://sites.google.com/site/daromasoft/home/ecdsoft ${ }^{[32]}$. Raw signals were first corrected 236 from noise using automatic smoothing (Savistky-Golay method ${ }^{[33]}$ ). Smoothed 237 voltammograms were then automatically subtracted by the blank (which was flat in the potential 238 range of $\mathrm{Cu}(\mathrm{SA})_{\mathrm{x}}$ peak). Additionally, the baseline at the position of $\mathrm{Cu}(\mathrm{SA})_{\mathrm{x}}$ peak was

239 manually subtracted for each voltammogram using the 'spline' procedure ${ }^{\text {[34] }}$. The reduction 240 peak corresponding to the $\mathrm{Cu}(\mathrm{SA})_{\mathrm{x}}$ complexes was found at $\sim 0.35 \mathrm{~V}$ (Figure 3 ). A 'shoulder' 241 was also observed on the positive side of the main $\mathrm{Cu}-\mathrm{SA}$ peak and could be linked to other $\mathrm{Cu}$-complexes existing in the sample, such as $\mathrm{Cu}$-sulfides nanoparticles ${ }^{[35-37]}$. 
246 Total dissolved $\mathrm{Cu}$ concentration in pretreated samples $\left(\mathrm{dCu}^{*}\right)$ was determined using 247 differential pulse anodic stripping voltammetry (DPASV). Prior to analysis, 10 to $20 \mathrm{~mL}$ of 248 hydrothermal fluid samples were acidified to $\mathrm{pH}<2$ (20 to $40 \mu \mathrm{L}$ of $\mathrm{HNO}_{3} 69 \%$, Suprapur) 249 and then UV-irradiated overnight (250 W high pressure mercury lamp). Electrochemical 250 paramaters were adapted from Omanović et al. ${ }^{[38]}$. Samples were first deaerated by purging the 251 solution for at least $5 \mathrm{~min}$. The accumulation was performed at a deposition potential of $-1 \mathrm{~V}$ 252 for 120 or $180 \mathrm{~s}$, followed by an anodic stripping scan from -0.45 to $0 \mathrm{~V}$ using the differential 253 pulse (DP) mode (modulation time $40 \mathrm{~ms}$, modulation amplitude $40 \mathrm{mV}$, step potential $2 \mathrm{mV}$ 254 and interval time $0.1 \mathrm{~s}$ ). A 2-s potential-jump to $-1.3 \mathrm{~V}$ was applied at the end of the 255 accumulation time. This step is needed for non-UV irradiated samples at natural $\mathrm{pH}$ in order to 256 desorb any layer of natural organic matter from the mercury drop ${ }^{[39]}$, but was also found to 257 slightly improve the baseline shape in acidic and UV-irradiated samples. The equilibration time 258 was set to $5 \mathrm{~s}$. $\mathrm{Cu}$ concentration was determined using the standard addition method. Every 259 measurement was repeated 3 times for quality control.

\subsection{Total dissolved $\mathrm{Cu}$ and $\mathrm{Mn}$ concentrations in untreated samples}

262 Untreated samples (both sets) were analyzed by HR ICP-MS (Element 2, Thermo Finnigan; at 263 IRB, Zagreb) and by ICP-AES (Ultima 2, Horiba Jobin Yvon; at PSO, Brest) for dCu and dMn 264 concentrations, respectively. The measurement of $\mathrm{dCu}$ concentrations was performed after 265 dilution of the samples from bags and PFA-bottles in a $2 \% \mathrm{HNO}_{3}$ solution (dilution factor: 10) 266 spiked with a stock solution of indium $\left(1\right.$ g. $\left.\mathrm{L}^{-1}\right)$ as internal standard (final concentration: $26710 \mu \mathrm{g} . \mathrm{L}^{-1}$ ). External standards of $\mathrm{Cu}$ were then prepared in the matrix matching media (UWSV, $2682 \% \mathrm{HNO}_{3}$ ) for the assessment of $\mathrm{dCu}$. The analysis of $\mathrm{dMn}$ was conducted on aliquots stored 
269 in $15 \mathrm{~mL}$ pre-cleaned polypropylene tubes (Elkay) dedicated for ICP measurements.

270 Preparation of solutions and standards is more detailed in Cotte et al. ${ }^{[40]}$. Blanks included

271 several replicates of the $2 \% \mathrm{HNO}_{3}$ solution as well as ultrapure water processed in the PEPITO

272 sampler. Repeatability $(\mathrm{n}=10)$ was $3 \%$ for $\mathrm{dMn}$ and $4 \%$ for $\mathrm{dCu}$. Dissolved concentrations

273 presented here were generally well above the detection limits. Blanks were below detection

274 limits and mostly negligible when compared to dissolved concentrations. It should be mentioned that acidification alone in sulfidic waters has been previously reported to result in a significant underestimation of total dissolved $\mathrm{Cu}$ because of the formation of stable $\mathrm{Cu}$ sulfide phases which can adsorb onto bottle walls ${ }^{[41]}$. However, overlooking total $\mathrm{dCu}$ concentrations is much more critical for the correct interpretation of the $\mathrm{dCu}$ spatial distribution in relation to the hydrothermal vent distance, than for the complexation study by which we tried to identify possible ligands (organic/sulfur derived) which control $\mathrm{Cu}$ speciation. Due to the complexity

of such studies, including sample collection, preservation, storage and, finally, measurement, it

is certain that some absolute values (e.g. concentrations of $\mathrm{dCu}$ ) do not correspond to the ambient conditions. However, the observed experimental/voltammetric phenomena are supposed to be mostly unaffected regardless of the total concentrations of some compounds.

\subsection{Dissolved organic carbon}

287 Samples were pipetted in glass tubes cleaned with $10 \% \mathrm{HNO}_{3}$ (analytical reagent grade), rinsed 288 with Milli-Q water and calcinated for 4 hours at $450^{\circ} \mathrm{C}$. Dissolved organic carbon (DOC) 289 measurement was conducted by direct injection of the sample into the furnace for combustion 290 at a temperature of $680^{\circ} \mathrm{C}$ through a highly sensitive catalyst $(\mathrm{Pt}){ }^{[42]}$. Formed $\mathrm{CO}_{2}$ was then 291 measured by a non-dispersive infrared analyzer (NDIR). Dissolved inorganic carbon (DIC) was

292 removed from the solution by acidification of each sample with a $2 \% \mathrm{HCl}$ solution to $\mathrm{pH} 2-3$ 293 and bubbling with clean air stream for $10 \mathrm{~min}$. Calibration was performed using potassium 
294 hydrogenophtalate as a standard. Sample from each cuvette was measured in triplicate and 295 standard deviation was calculated $\left(0.01 \mathrm{mg} \cdot \mathrm{L}^{-1}\right)$. Note that DOC was only measured on the 2016 296 samples.

\section{Results and discussion}

\subsection{Master variables}

300 All $\mathrm{Cu}$ speciation parameters and the associated master variables measured in the present study 301 are summarized in Table 1, Table 2 and Table 3. Dissolved manganese (dMn) was used as 302 conservative tracer because of its well-known very slow scavenging rate in the plume ${ }^{[43,44]}$. As 303 expected, samples from the early buoyant plume were highly enriched in $\mathrm{dMn}$ at both sampling 304 sites compared to typical deep-seawater concentrations ( $\mathrm{dMn} \sim 0.5 \mathrm{nM}$ at $1700 \mathrm{~m}$ depth $\left.{ }^{[45]}\right)$. 305 The 3 sets of samples collected at Aisics (2015 and 2016) and Y3 (2015) displayed dMn 306 concentrations ranging from 1 to $\sim 100 \mu \mathrm{M}$ indicating that the examined area corresponds to a 307 dilution of the hydrothermal solution with local seawater of $\sim 3$ to $\sim 300$ (Table S1). In addition, 308 similar $\mathrm{T}-\mathrm{dMn}$ linear relationships were observed at both vent sites $(\mathrm{T} \sim 1.5 \mathrm{dMn})$.

309 Dissolved $\mathrm{Cu}$ concentrations $(\mathrm{dCu})$ in untreated samples were generally found in the range 10 $310800 \mathrm{nM}$ at both vent sites with values from 12 to $771 \mathrm{nM}$ and from 13 to $409 \mathrm{nM}$ at Aisics and 311 Y3, respectively (Table 1). This is much higher (one or two orders of magnitude) than the 312 ambient concentrations reported in deep-seawater of the North Atlantic $\left(2-3 \mathrm{nM}{ }^{[46,47]}\right)$ but 313 typical of hydrothermal input. As opposed to $\mathrm{dMn}$, concentrations for $\mathrm{dCu}$ differed between the 314 two vent sites, Y3 displaying globally higher $\mathrm{dCu}$ concentrations than Aisics $(\mathrm{dCu}=5.6 \mathrm{dMn}$ vs. $\mathrm{dCu}=3.0 \mathrm{dMn}$, respectively). This discrepancy suggests different physico-chemical 
a low year-to-year variability of $\mathrm{dCu}$ in the mixing gradient was observed for the 2 sampling years (Table 1 and Table 2).

319 In pretreated samples, dissolved $\mathrm{Cu}$ concentrations $\left(\mathrm{dCu}^{*}\right)$ were much lower than the original $320 \mathrm{dCu}$. Indeed, $\mathrm{dCu}^{*}$ at Aisics varied between 2.5 and $14 \mathrm{nM}$ whereas corresponding $\mathrm{dCu}$ ranged 321 from 7 to $410 \mathrm{nM}$ (Table 2). Such difference arises from the removal of the $\mathrm{dCu}$ by adsorption 322 onto the PFA bottle walls over the storage period and by additional scavenging onto the newly323 formed particles resulting from the air-purging treatment.

\subsection{In situ concentrations of sulfides and oxygen}

326 Concentrations of in situ free sulfides $\left(\Sigma \mathrm{S}=\mathrm{HS}^{-}+\mathrm{S}^{2-}+\mathrm{H}_{2} \mathrm{~S}\right)$ and dissolved oxygen are 327 summarized in Table 3. In situ concentrations of $\Sigma \mathrm{S}$ ranged from 1 to $320 \mu \mathrm{M}$ and from 5 to $328350 \mu \mathrm{M}$ at Aisics in 2015 (dive 02598) and in 2016 (dive 09632), respectively. The $\Sigma \mathrm{S}$ 329 concentrations were slightly higher at Y3 as they were ranging from 52 to $415 \mu \mathrm{M}$. Like for $330 \mathrm{dCu}$, this difference could be due to a different chemical signature of each end-member fluid. 331 Note that the $\Sigma \mathrm{S}$ data were not measured in 2015 at $\mathrm{Y} 3$. We thus chose to use the $\Sigma \mathrm{S}$ data 332 measured in 2014 at the same site. Such earlier data can be considered representative of free sulfide conditions occurring at Y3 considering the very low variability observed for other 334 chemical parameters at that site between 2014 and $2015^{[48]}$. As expected, in situ $\Sigma$ S levels were 335 increasing with $\mathrm{dMn}$ and T, towards the vent orifice (Figure 5, Figure 6 and Figure 7). Note 336 however the positive anomaly in $\Sigma \mathrm{S}$ observed at Aisics where $\Sigma \mathrm{S}$ concentrations reach more 337 than $300 \mu \mathrm{M}$ at around $50 \mu \mathrm{M}$ of dMn (Figure 5). Changes in the in situ dissolved oxygen $\left(\mathrm{O}_{2}\right)$ 338 levels along the mixing gradient were not as steep as it was noticed for $\Sigma$ S. Concentrations were 339 indeed slowly decreasing with increasing $\mathrm{dMn}$ concentrations from 276 to $146 \mu \mathrm{M}$ $340(\operatorname{avg}=200 \mu \mathrm{M})$ and from 264 to $183 \mu \mathrm{M}(\operatorname{avg}=230 \mu \mathrm{M})$ at Aisics and Y3, respectively (Table $3413)$. The two vent sites generally displayed similar oxygen levels throughout the mixing gradient, 


\subsection{Description of the voltammograms}

In our hydrothermal samples, voltammograms differed from those classically obtained in seawater because of the occurrence of interferences on the $\mathrm{Cu}(\mathrm{SA})_{\mathrm{x}}$ signal as well as several additional peaks. As their description can provide an 'imprint' of the hydrothermal environment, a complete scan from 0.05 to $-1.6 \mathrm{~V}$ was performed during stripping. None of 350 these interferences or additional peaks were detectable when analyzing UVSW, indicating a 351 natural origin of the compounds involved and not an artifact from the method. In this section, 352 we investigate on the nature of these additional peaks thanks to laboratory tests and literature. 353 We then discuss on the interferences affecting the $\mathrm{Cu}(\mathrm{SA})_{\mathrm{x}}$ signal.

\subsubsection{On the nature of additional peaks}

355 Voltammograms for untreated and pretreated samples are presented in Figure 3. The peak at $3561.45 \mathrm{~V}$ was related to the reduction of $\mathrm{dMn}$ (it is not accumulated) as the peak height was 357 increasing in response to $\mathrm{Mn}(\mathrm{II})$ additions (Figure S1). As expected, the closer from the vent 358 orifice, the higher was the dMn signal (Figure S2).

359 The massive signal observed at $-0.6 \mathrm{~V}$ vs. $\mathrm{Ag} / \mathrm{AgCl}$ in pretreated samples (Figure $3 \mathrm{~B}$ ) could be 360 related to the high ambient reduced sulfur species (RSS) ${ }^{[49,50]}$ in our samples, in line with the 361 high in situ concentration of $\Sigma \mathrm{S}$ measured (up to $300 \mu \mathrm{M}$ ). The signal is much lower but still 362 visible in untreated samples (Figure 3A). The peak likely corresponds to the dissolution363 reduction of an $\mathrm{HgS}$ layer deposited on the mercury drop surface as reported in many studies ${ }^{[50-}$

$364{ }^{55]}$. Many sulfur species could contribute to the $\mathrm{HgS}$ layer deposition especially sulfides (HS ${ }^{-}$ 365 and $\left.\mathrm{S}^{2-}\right)$, but also dissolved elemental sulfur $\mathrm{S}^{0}(<0.2 \mu \mathrm{m})$, polysulfides $\left(\mathrm{S}_{\mathrm{n}}{ }^{2-}\right)^{[52,56]}$ or metal 
366 sulfide nanoparticles ${ }^{[35-37,57,58]}$. According to the excess of the in situ free sulfide concentrations

367 measured, free sulfides should be the dominant RSS in our samples. In the experimental 368 conditions used $(\mathrm{pH} \sim 8), \mathrm{HS}^{-}$might be the dominant free sulfide species and the formation of 369 the insoluble $\mathrm{HgS}$ layer at deposition potential more positive than $-0.5 \mathrm{~V}$ could therefore be 370 expressed according to the following reversible two-electron process ${ }^{[49]}(1)$ :

$$
\mathrm{HS}^{-}+\mathrm{Hg}^{0} \leftrightarrow \mathrm{HgS}_{\text {layer }}+\mathrm{H}^{+}+2 \mathrm{e}^{-}
$$

As dissolved Fe concentrations are relatively high in untreated samples $\left(\sim 2-200 \mu \mathrm{M}^{[48]}\right)$, we cannot exclude that some dissolved Fe would still persist as Fe(II) species, even after the pretreatment. If so, the diffusion of labile $\mathrm{Fe}(\mathrm{II})$ to the $\mathrm{Hg}$ electrode may change the $\mathrm{HgS}$ layer formed with sulfides to a FeS layer ${ }^{[58]}(2)$ :

$$
\mathrm{HgS}_{\text {layer }}+\mathrm{Fe}^{2+}+2 \mathrm{e}^{-} \leftrightarrow \mathrm{FeS}_{\text {layer }}+\mathrm{Hg}^{0}
$$

FeS layers could also be generated by the direct deposition of FeS nanoparticles at the electrode surface ${ }^{[58]}$. Since the FeS layers deposited are re-dissolved at around $-0.6 \mathrm{~V}^{[58]}$, they could partly contribute to the massive signal observed in pre-treated samples. In addition to sulfide species, thiols could also contribute to the large peak observed, this compounds providing a peak at the same potential ${ }^{[59,60]}$. It is also important to underline that the height of the peak at $0.6 \mathrm{~V}$ was decreasing with additions of $\mathrm{Cu}$ (Figure 3B). This suggests that the specie(s) 385 involved, i.e. sulfides or thiols, is(are) reacting with the added $\mathrm{Cu}$ throughout the titration experiment ${ }^{[50,60]}$.

387 The peak at $-0.1 \mathrm{~V}$, which does not increase with the accumulation time, observable for both 388 untreated and pretreated samples could be related to three different reduction processes (Figure 
3). The first one could be iodide which was found to occur at that potential in estuarine samples,

390 though easily removed through the application of a desorption step at more negative potential

$391{ }^{[17]}$. Unfortunately, neither the addition of potassium iodide in the buffered samples ( $\mathrm{pH} 8.2$, not

392 shown), nor the application of the 1-s jumping potential did produce any increasing or removal 393 of the peak of interest, respectively. Combined with the fact that iodide is not a major compound 394 of hydrothermal fluid compared to chloride, this first hypothesis was thus excluded. Another 395 possible explanation could be the deposition of a copper-sulfide layer on the drop surface as a 396 result of an exchange reaction between $\mathrm{Hg}^{2+}$ from the $\mathrm{HgS}$ layer and labile $\mathrm{Cu}$ in solution, 397 according to the reversible reaction (3) ${ }^{[55]}$ :

398

$$
\mathrm{HgS}_{\text {layer }}+\mathrm{Cu}^{2+}+2 \mathrm{e}^{-} \leftrightarrow \mathrm{CuS}_{\text {layer }}+\mathrm{Hg}^{0}
$$

400 Labile $\mathrm{Cu}$ could correspond to weak $\mathrm{Cu}$-complexes or, potentially, $\mathrm{Cu}$-sulfides nanoparticles 401 (clusters). Such process has been shown to happen for many metal as $\mathrm{Zn}^{2+}$ or $\mathrm{Fe}^{2+}$ but only the 402 formation of the $\mathrm{CuS}$ layer provides a signal at $-0.1 \mathrm{~V}$ vs $\mathrm{Ag} / \mathrm{AgCl}$ (e.g. $\mathrm{E} \sim-0.6 \mathrm{~V}$ for the $\mathrm{FeS}$ layer) ${ }^{[53,55]}$. Once deposited, the $\mathrm{CuS}$ layer will be reduced at $\sim-1.0 \mathrm{~V}$ vs $\mathrm{Ag} / \mathrm{AgCl}{ }^{[35-37,55]}$ as 404 described in reaction (4) :

$$
\mathrm{CuS}_{\text {layer }}+\mathrm{H}^{+}+2 \mathrm{e}^{-} \rightarrow \mathrm{Cu}^{0}+\mathrm{HS}^{-}
$$

407 Among voltammograms of untreated samples, this reduction peak was sometimes noticeable 408 (up to $15 \mathrm{nA}$, Figure 3A). In pretreated samples, this signal was not observed, probably because 409 hindered by the massive $\mathrm{HgS}$ reduction peak. The peak potential of the $\mathrm{CuS}$ formation process 410 (3) is determined by the solubility product $\mathrm{K}_{\mathrm{sp}}$ of $\mathrm{CuS}{ }^{[55]}$. Through the titration experiment, $\mathrm{K}_{\mathrm{sp}}$ 411 will increase with increasing addition of $\mathrm{Cu}$ whereas $\mathrm{pK}_{\mathrm{sp}}$ will decrease. Consequently, the peak 
412 potential will be slightly shifted towards more negative potential as shown by Milanović et al.

$413{ }^{[55]}$. This feature was not observed when performing titrations, except some slight shifting of

414 the presumed $\mathrm{CuS}$ peak toward more positive potential in few cases (Figure 3A). In addition

415 with the potential shifting observed, the peak height was not dependent on the accumulation

416 time. However, the peak height was increasing when getting closer to the vent source (Figure

417 S2). This led us to the final assumption that the peak of interest could be related to thiosulfate,

418 which is known to be formed in hydrothermal vents by the slow oxidization of sulfides ${ }^{[61]}$.

419 Thiosulfate $\left(\mathrm{S}_{2} \mathrm{O}_{3}{ }^{2-}\right)$ reduction occurs at around $-0.1 \mathrm{~V}$ vs $\mathrm{Ag} / \mathrm{AgCl}$ and is well separated from

420 the global sulfides reduction peak $(-0.6 \mathrm{~V})$ at $\mathrm{pH} 8^{[51,52]}$. The interaction between thiosulfate

421 and mercury results in the formation of a soluble complex via the oxidation of $\mathrm{Hg}$ according to

422 the two electron process (5):

423

$$
2 \mathrm{~S}_{2} \mathrm{O}_{3}^{2-}+\mathrm{Hg}^{0} \leftrightarrow\left[\mathrm{Hg}\left(\mathrm{S}_{2} \mathrm{O}_{3}\right)_{2}\right]^{2-}+2 \mathrm{e}^{-}
$$

The soluble complex cannot be pre-concentrated to the drop surface as it immediately goes back to solution after its formation (as mentioned above, this peak does not increase with the accumulation time). The cathodic scan enables then to strip only the quantity of $\left[\mathrm{Hg}\left(\mathrm{S}_{2} \mathrm{O}_{3}\right)_{2}\right]^{2-}$ formed on the drop surface at that precise moment, the current measured corresponding to the reduction of $\mathrm{Hg}^{2+}$ to $\mathrm{Hg}^{0[51]}$. Unfortunately, addition of sodium thiosulfate was not performed on samples to confirm this assumption. Besides, the aforementioned studies were working on

431 laboratory solutions with known concentrations of all species in solution or on samples not truly representative of hydrothermal samples. Accordingly, the identification of each electroactive species in such unusual samples must be more problematic and more tests should be further

434 carried out to decide which process is truly happening. Hence, the peak at $-0.1 \mathrm{~V}$ vs $\mathrm{Ag} / \mathrm{AgCl}$

435 could be both related to the $\mathrm{CuS}$ layer formation and to the thiosulfate reduction. 


\subsubsection{Interferences on the $\mathrm{Cu}(\mathrm{SA})_{\mathrm{x}}$ signal}

Interferences on the $\mathrm{Cu}(\mathrm{SA})_{\mathrm{x}}$ signal were observed in most of hydrothermal samples (Figure 3). At low addition of $\mathrm{Cu}$, unknown peak/shoulder at $\sim-0.27 \mathrm{~V}$ was systematically overlapping with the $\mathrm{Cu}(\mathrm{SA})_{\mathrm{x}}$ signal in both untreated and pretreated samples. A similar shoulder is observable in voltammograms presented on the 'Figure 1.b' of Sander et al.'s paper ${ }^{[10]}$. In both datasets, the corresponding reduction signal was thus fitted and de-convolved from the interferences observed at $\sim-0.27 \mathrm{~V}$ using the ECDSOFT program. Depending on the sample, 1 or 2 peaks were considered to overlap with the main $\mathrm{Cu}(\mathrm{SA})_{\mathrm{x}}$ reduction peak. Signal deconvolution was performed by starting from the signal corresponding to the highest $\mathrm{Cu}$ addition, where interferences no longer overlook the $\mathrm{Cu}(\mathrm{SA})_{\mathrm{x}}$ reduction peak, towards the signal corresponding to the lowest $\mathrm{Cu}$ addition, where extraction was more liable to errors. The height of the de-convolved peak of $\mathrm{Cu}(\mathrm{SA})_{\mathrm{x}}$ was then measured and used to construct the final titration curves which consist in the relationship between the measured current $\left(i_{p}\right)$ and the total concentration of $\mathrm{Cu}$ (Figure 4).

Note that the $\mathrm{Cu}(\mathrm{SA})_{\mathrm{x}}$ signal at $\sim-0.3 \mathrm{~V}$ obtained for pretreated samples was not well defined, especially at low additions of $\mathrm{Cu}$ where it appears flattened and narrower compared to the one observed in untreated samples (see boxed window (*), Figure 3B). The spike observed did not correspond to a reversible process which suggest that it was not related to the reduction of the $\mathrm{Cu}(\mathrm{SA})_{\mathrm{x}}$ complex. With increasing additions of $\mathrm{Cu}$, the spike was shifting towards more positive potential $(-0.27 \mathrm{~V})$ until the appearance of a second peak corresponding to the reversible reduction of the $\mathrm{Cu}(\mathrm{SA})_{\mathrm{x}}$ complexes at $-0.3 \mathrm{~V}$. In addition, the maximum reduction current for the $\mathrm{Cu}(\mathrm{SA})_{\mathrm{x}}$ signal, corresponding to the last addition of $\mathrm{Cu}$ (same final concentration), was $\sim 200 \mathrm{nA}$ in pretreated samples whereas it reached almost $400 \mathrm{nA}$ for 
untreated samples. These issues are likely related to the $\mathrm{HgS}$ layer formed at the mercury drop.

461 By occupying most of the space available on the drop, the HgS layer probably prevents the

$462 \mathrm{Cu}(\mathrm{SA})_{\mathrm{x}}$ complexes from adsorbing on the drop surface. This feature has already been observed

463 by Powell ${ }^{[11]}$ who mentioned both an over-scale reduction peak at $-0.5 \mathrm{~V}$ (vs Ag/AgCl) related

464 to RSS and a poorly defined $\mathrm{Cu}(\mathrm{SA})_{\mathrm{x}}$ peak, but before any pre-treatment of his hydrothermal

465 samples. Consequently, the HgS layer formation as well as its reduction are interfering on the

$466 \mathrm{Cu}(\mathrm{SA})_{\mathrm{x}}$ signal, although the two reduction peaks are not overlapping.

467 In an attempt to remove the $\mathrm{HgS}$ interference, a 1-s potential-jump to - $0.65 \mathrm{~V}$ to desorb the $\mathrm{HgS}$

468 layer from the drop was performed to the air-purged samples at the end of the accumulation

469 step. This desorption step effectively removed $>95 \%$ of the $\mathrm{HgS}$ interference. However,

470 comparative experiments in model and real samples showed that this procedure is providing

471 good results on model samples whereas its application on real hydrothermal samples still needs

472 to be more explored, because of problems with the linearity. Though unsuccessful, the

473 procedure employed is described in supplementary information. Note that the $\mathrm{HgS}$ interference

474 should also be high in untreated samples since the in situ concentrations of $\Sigma$ S are similar than

475 for pretreated samples. It was not the case because untreated samples were 10-fold diluted and

476 were analyzed a year after collection, meaning that most of the free RSS could have been slowly

477 oxidized with time by $\mathrm{O}_{2}$ excess in samples (e.g. $\sim 200 \mu \mathrm{M}$, Figure 5 ) or potentially by slight

478 air passing through sampling bags. By contrary, pretreated aliquots were analyzed only 2

479 months after sampling, meaning that a short time is required between sampling and

480 electrochemical analysis for speciation studies. In conclusion, fairly good titration curves were

481 obtained from the classical analysis used for speciation studies ${ }^{[28]}$ but titration of the $\mathrm{Cu}$ -

482 binding ligands was more problematic than expected in 2016 because of the high ambient sulfur

483 species. Despite not fully identified, sulfur species obviously play a major role in the early

484 buoyant plume and likely interfere on $\mathrm{Cu}$ speciation measurement in this area. 


\subsection{Cu-complexing ligand parameters}

487 Concentrations for $\mathrm{Cu}$-binding ligands ([L]) in the untreated samples ranged from 0.032 to $3 \mu \mathrm{M}$ (avg. $700 \mathrm{nM}, \mathrm{n}=19$; Table 1). Aisics and Y3 both exhibited similar concentrations for [L] which varied between 0.23 and $3 \mu \mathrm{M}$ and from 0.032 to $1 \mu \mathrm{M}$, respectively. Interestingly, an increasing trend towards the plume core clearly appears when plotting both [L] and $\Sigma \mathrm{S}$ against the dMn concentrations at Y3 (Figure 6). This suggests a common source for all these parameters including the Cu-binding ligands. This feature has already been observed close to deep-sea vents for Fe-binding ligands which were highly correlated with the hydrothermally sourced Fe concentrations $\left(r^{2}=0.996\right)^{[16]}$. The trend was less clear at Aisics where [L] were globally flattened by two samples displaying the highest concentrations measured (02598 B1 and $02598 \mathrm{D} 3$ ) (Figure 5). Note that the corresponding dCu concentrations in these two samples were also the highest measured (770 and $460 \mathrm{nM}$, resp.), indicating that these two exceptions for [L] were not an artefact from the titration experiments. However, it should be mentioned that, when these two 'outliers' are not considered, a very good match between [L] and the anomaly of $\Sigma S$ is observed (not shown). Stability constants $\left(\log K_{C u L}^{\prime}\right)$ remained globally similar at both sites: calculations provided $\log \mathrm{K}_{\mathrm{CuL}}^{\prime}$ values ranging from 12.37 to 13.38 (avg. 12.89).

To our knowledge, Sander et al. ${ }^{[10]}$ and Klevenz et al. ${ }^{[62]}$ are the only studies for which titration experiments have been conducted on untreated hydrothermal samples (i.e. non-acidified, nonpurged) and thus to which our results for L can be directly compared. Our untreated samples displayed $[\mathrm{L}]$ in similar range than concentrations previously measured at the Kermadec Arc in

507 Pacific ${ }^{[10]}$. The authors have indeed reported concentrations for $\mathrm{Cu}$-binding ligands ranging 508 from $125 \mathrm{nM}$ to $4.5 \mu \mathrm{M}$ (avg. $1.7 \mu \mathrm{M}, \mathrm{n}=4$ ). However, Klevenz et al. ${ }^{[62]}$ have reported narrower concentration ranges $(50-200 \mathrm{nM})$ from diffuse hydrothermal fluids of the MAR, 
510 with an average value of $125 \mathrm{nM}(\mathrm{n}=2)$. Interestingly, our obtained stability constants 511 (12.37-13.38, avg. $12.89 \pm 0.11)$ are also very close to those observed by Sander et al. ${ }^{[10]}$, 512 i.e. $\log \mathrm{K}_{\mathrm{CuL}}$ ranging from 12.53 to 13.46 (avg. $12.88 \pm 0.61$ ). A similar ligand class has 513 therefore been measured in both cases, suggesting that the $\mathrm{Cu}$-binding ligands found are likely 514 to be of same nature. Although Sander and co-workers have attributed their findings to the 515 occurrence of strong organic ligands (i.e. thiols), it is also worth mentioning that a $\log \mathrm{K}^{\prime} \mathrm{CuL}$ 516 value of 12.9 has been found for $\mathrm{Cu}$-bisulfide complexes using ligand competition with oxine 517 at $\mathrm{pH} 8^{[50]}$. Regarding their similar stability constants, both strong organic and inorganic 518 bisulfide ligands could therefore be considered as part of the $\mathrm{Cu}$-binding ligands mixture. It 519 should be mentioned that both $\mathrm{Cu}(\mathrm{I})$ or $\mathrm{Cu}(\mathrm{II})$ species could be part of the $\mathrm{Cu}$-complexes detected. The existence of $\mathrm{Cu}(\mathrm{I})$ is probable in hydrothermal samples because of the complex redox reactions in which $\mathrm{Cu}$ is involved ${ }^{[63]}$. The existing $\mathrm{Cu}(\mathrm{I})$ species could be further stabilized by complexation with thiols, as previously suggested ${ }^{[64,65]}$. In our case, the oxidation of $\mathrm{Cu}(\mathrm{I})$ during sample storage is likely to occur ${ }^{[66]}$ and it would be too speculative to claim that the observed $\mathrm{Cu}$ speciation is mainly related to $\mathrm{Cu}(\mathrm{I})$-thiol compounds. However, the formation of $\mathrm{Cu}(\mathrm{I})$-thiol complexes should also be considered with specific experiment designed in order to prove such complexation scenario.

\subsection{On the nature of dissolved copper ligands in the buoyant plume}

529 Below, we discuss the potential sources of $\mathrm{Cu}$-binding ligands (organic and/or inorganic) which 530 could explain at best the high concentrations for L measured in our samples, in line with our

531 available data set for DOC and for in situ free sulfides. We then consider copper speciation 532 under laboratory conditions and discuss the implications deduced from $\left[\mathrm{L}^{*}\right]$ on the persistence 533 of hydrothermal Cu-binding ligands in the oxic water column. 


\subsubsection{Organic Cu-ligands}

535 DOC in deep ocean waters is mainly composed of refractory organic matter originally coming 536 from sea surface ${ }^{[67]}$ and resistant enough to removal processes such as microbial activity. In 537 deep waters, background concentrations of refractory DOC are averaging $45 \mu \mathrm{M}^{[68,69]}$ whereas 538 concentrations detected in focused and diffuse vents range on average from 15 to $\sim 100 \mu \mathrm{M}$ $539{ }^{[70,71]}$ and from 50 to $\sim 100 \mu \mathrm{M}^{[70-72]}$, respectively. The oldest (or most refractory) forms of the 540 deep DOC pool are almost all removed (>90\%) through thermal degradation in subseafloor 541 circulation ${ }^{[71,73]}$ but, still bulk DOC concentrations remain important because of carbon-rich 542 sediment remobilization as well as local input of abiotically-produced organics compounds $543[4,71]$

Our samples display DOC concentrations ranging from 25 to $90 \mu \mathrm{M}$ (avg. $53 \mu \mathrm{M}$ ) which is slightly above background DOC in deep seawater $(45 \mu \mathrm{M})$ but in the range of previous finding in hydrothermal vents. The highest value corresponded to one of the closest sample from the vent source (09632 C3) (Table 2) though no particular trend has been noticed along the mixing gradient. In surrounding deep Atlantic waters, concentrations of organic ligands have been 550 reported to be in the range of $2-4 \mathrm{nM}^{[47]}$. So, basically, organic ligands from deep seawater account for $0.01 \%$ of the deep recalcitrant DOC pool. More importantly, those organic ligands can only provide a very limited part of the Cu-binding ligands observed here (up to $3 \mu \mathrm{M}$ ). A

553 deep local source must therefore explain the enhanced concentrations measured for L.

554 First, organic compounds including organosulfur $\mathrm{Cu}$-ligands could be directly produced in the 555 hydrothermal fluid, before venting ${ }^{[74]}$. Synthesis of thiols through abiotic reduction of the 556 hydrothermally-sourced inorganic carbon $\left(\mathrm{CO}_{2}\right.$ or $\left.\mathrm{CO}\right)$ has indeed been suggested for $\mathrm{H}_{2}$-rich 557 fluids ${ }^{[75]}$. However, this process has been reported to be limited. In addition, the hydrothermal 558 fluids from Lucky Strike show relatively low levels in $\mathrm{H}_{2}$ when compared to other sites from 
559 the MAR such as Rainbow ${ }^{[76]}$. Instead, thermal degradation of microbial communities with the 560 associated dissolved organic matter in subsurface has been suggested to produce methanethiols. 561 The abundance of such specific compounds has been reported to be around $10 \mathrm{nM}$ in high 562 temperature fluids $\left(>200^{\circ} \mathrm{C}\right)^{[4]}$. Indeed, the authors have performed measurements of 563 methanethiols in the end-members fluids of 4 smokers located in the Lucky Strike vent field.

564 The resulting concentrations were around 6-7 $\mathrm{nM}$ with a maximum of $23 \mathrm{nM}$ (avg. $10 \mathrm{nM}$ ).

565 Since the Aisics and $\mathrm{Y} 3$ end-members both display temperatures greater than $300^{\circ} \mathrm{C}$ (Table S1), 566 the abundance of methanethiols are likely to be in a similar range, i.e. lower than $20 \mathrm{nM}$.

567 Second, organosulfur ligands with available binding sites could be supplied by microbial 568 production in diffuse areas. If located in the close vicinity of focused black smokers 569 (e.g. Aisics), then microbially-produced ligands could be laterally entrained in the buoyant 570 plume, as suggested for larvae ${ }^{[77]}$. Cultured microbes from two hydrothermal vents of the MAR 571 have indeed been reported to produce organic $\mathrm{Cu}$-binding ligands as a protection against the 572 enhanced $\mathrm{Cu}$ concentrations ${ }^{[62]}$. In response to the addition of $100 \mathrm{nM}$ of $\mathrm{Cu}$, around $200 \mathrm{nM}$ 573 of Cu-binding ligands were produced in one of the cultures, which is not negligible but still not 574 completely explaining the enhanced level for L in the present study.

575 Finally, laterally entrained microbial communities could produce organics directly in the early 576 buoyant plume, where temperature falls down rapidly under $100^{\circ} \mathrm{C}$. However, we anticipate 577 that the early mixing of the studied gradients (on the order of ten seconds) should be much 578 faster than microbial production of organic compounds. Although not known for hydrothermal 579 microbes, the kinetic of production for organic ligands by phytoplankton in response to metal 580 enrichments has been found to be around $1 \mathrm{nM}$ per day for specific zinc-binding compounds $581{ }^{[78]}$, which is much longer than the mixing time.

582 Overall, deep local sources of potential organic $\mathrm{Cu}$-ligands are existing in deep-sea 583 hydrothermal vents but the input appears to be relatively limited and can only explain a small 
584 part of the Cu-binding ligands measured in the buoyant plume. As none carbon-rich sediment 585 remobilization has been noticed during sampling - the lava lake is moderately covered by 586 sediment ${ }^{[20]}$ - other sources as well as other type of ligands should be considered such as the 587 input of inorganic Cu-binding ligands by vent sources. It is worth noting however, that the 588 fraction of $\mathrm{Cu}$-ligands resistant to the air purging treatment $\left(\mathrm{L}^{*}\right)$ could correspond to organic species. Their concentrations, up to 20 fold lower than those of the ligands L (range 18-44 nM;

590 Table 2) appear to be on the same order of magnitude than the aforementioned potential organic 591 sources. Their stability constants $\left(\log \mathrm{K}^{\prime *} \mathrm{CuL}\right)$ range from 12.57 to 13.04 (avg. 12.79) and are thus comparable to those found for thiols ${ }^{[10,60]}$. When plotting $\left[\mathrm{L}^{*}\right]$ against $\mathrm{dMn}$ at Aisics

593 (Figure 7), the highest concentrations for $\mathrm{L}^{*}$ were observed closer to the hydrothermal end594 member, at dMn concentrations about $75 \mathrm{nM}$ (corresponding to a temperature of $\sim 120^{\circ} \mathrm{C}$ ). This 595 feature suggests that the ligands $\mathrm{L}^{*}$ are hydrothermally sourced. Nevertheless, more samples 596 would have been needed in the hotter part of the mixing to confirm this assumption.

\subsubsection{Inorganic Cu-ligands}

599 Chloride and sulfides are recognized to be the dominant inorganic $\mathrm{Cu}$-binding ligands in 600 hydrothermal fluids ${ }^{[9,79]}$. While $\mathrm{Cu}(\mathrm{I})$-chloride complexes dominate in hot $\left(\sim 300^{\circ} \mathrm{C}\right)$ and acidic $601(\mathrm{pH}<3)$ fluids ${ }^{[80]}$, $\mathrm{Cu}$-sulfides complexes become predominant at temperature lower than $602150^{\circ} \mathrm{C}$ with increasing $\mathrm{pH}^{[79]}$. Upon mixing with seawater, the temperature of hydrothermal 603 fluids rapidly falls down under $150^{\circ} \mathrm{C}$ leading to weaker $\mathrm{Cu}$-chloride complexes. Cooling 604 promptly establishes a competition between chloride and sulfides for $\mathrm{Cu}$ and $\mathrm{Cu}$-sulfides 605 complexes progressively overlook the $\mathrm{Cu}$-chloride complexes ${ }^{[80]}$.

606 Because of their high stability constant, comparable to that of strong organic ligands and their 607 massive concentrations measured in situ $(>100 \mu \mathrm{M})$ (Figure 5, Figure 6 and Figure 7), we infer 608 that inorganic sulfides could be the main contributors of the enhanced $\mathrm{Cu}$-binding ligands 
concentrations observed in the early mixing. This assumption is supported by the fact that the

$610 \log \mathrm{K}_{\mathrm{CuL}}^{\prime}$ value we found at deep-sea vents were very similar to those reported by Al-Farawati 611 and van den Berg ${ }^{[50]}$ for $\mathrm{Cu}(\mathrm{HS})$ complexes (i.e. 12.9). Moreover, the in situ concentrations of 612 inorganic sulfides are greater than $100 \mu \mathrm{M}$ in most of our samples (Table 3). At such level of 613 inorganic sulfides, Al-Farawati and van den Berg have shown that the competition between 614 organic ligands and bisulfide for $\mathrm{Cu}$ does not exist anymore since the effect of organic compounds on $\mathrm{Cu}$-speciation becomes negligible when bisulfide concentrations are greater than $1 \mathrm{nM}$. The slow kinetics reported for the abiotic oxidation of sulfides by oxygen in diffuse hydrothermal vents strengthen this hypothesis ${ }^{[61]}$. The authors have indeed calculated sulfides 618 oxidation rate lower than $1 \mathrm{nM} \cdot \mathrm{min}^{-1}$ which is negligible when compared to the mixing velocity 619 of the early buoyant plume $\left(22-119 \mathrm{~cm} \cdot \mathrm{s}^{-1}{ }^{[81]}\right)$ and to the total sulfides concentrations. 620 Furthermore, using in situ voltammetry, they did not find enhanced concentrations of sulfur 621 oxidation intermediate (i.e. thiosulfate or polysulfides), attesting to the slow oxidization process 622 of $\mathrm{H}_{2} \mathrm{~S}$ and $\mathrm{HS}^{-}$in the mixing ${ }^{[61]}$.

$623 \mathrm{As} \mathrm{pH}$ is around 5 for all samples, the inorganic sulfide species should be mainly found as $\mathrm{H}_{2} \mathrm{~S}$ 624 and $\mathrm{HS}^{-}$. With the progressive mixing with seawater, $\mathrm{pH}$ will gradually increase until 7-8, and 625 sulfides will be mostly found as bisulfides $\mathrm{HS}^{-}$. Consequently, the inorganic $\mathrm{Cu}$-sulfide 626 complexes should be mainly found as $\mathrm{Cu}(\mathrm{HS})^{+}$or as $\mathrm{Cu}(\mathrm{HS})_{2}{ }^{[50]}$ and, in any case, should 627 largely overtake the organic ligands in the early mixing. Elemental sulfur $\mathrm{S}^{0}$ could also interact 628 with the ambient $\mathrm{Cu}^{[11]}$, though it is hard to know to which extent in the present study. However, 629 with the aging of the plume, local mixing of the plume with biologically rich diffuse vents 630 should lead to the input of organic ligands (e.g. thiols) which would mainly come from biotic 631 interactions. Such input would then increase the impact of organic ligands on the speciation of $632 \mathrm{Cu}$. We hypothesize that organosulfur compounds and stabilized sulfides (i.e. bound to $\mathrm{Cu}$ or 
633

634 inorganic copper-sulfides complexes.

635

636

637

638

640

641

642 shapes and final results.

another metal) might coexist in the neutrally buoyant plume, until the complete oxidation of the

\subsection{Chemical changes of in situ speciation in laboratory conditions}

As soon as samples are collected, free sulfides start going through progressive oxidation because of the excess of $\mathrm{O}_{2}$ in samples as well as some potential slight air-passing through the bags/bottles. Despite this slow removal, our results show that free sulfides still control $\mathrm{Cu}$ speciation at least 2 months after sampling. Facing such dominance, all previous studies aiming at defining organic copper complexation in hydrothermal vents have performed an acidification pre-treatment $(\mathrm{pH}<2)$ followed by $\mathrm{N}_{2}$-purging to remove any ambient $\mathrm{RSS}^{\left[{ }^{82}\right]}$ in order to measure only labile $\mathrm{Cu}$ released from the remaining organic ligands ${ }^{[10-12]}$. As mentioned previously, we tested this protocol, but did not observe any difference in the voltammogram

In an attempt to distinguish the organic part from the ligand pool and to fasten the process of sulfur species oxidation which already started inside of the PFA bottle, we simply air-purged and re-filtered at $0.2 \mu \mathrm{m}$ samples ( $2^{\text {nd }}$ set) for titrations of $\mathrm{Cu}$-binding ligands. Lower $\mathrm{Cu}$ binding ligands concentrations were systematically found in these pretreated samples, attesting that sulfides species removed are part of the $\mathrm{Cu}$-ligands measured. On the contrary, air purging would not have impacted organic ligands that much. Assuming that $\mathrm{L}^{*}$ mostly stand for organic ligands, i.e. strong organosulfur ligands as thiols ${ }^{[10]}$, the organic pool still constitute a limited part of the global ligand pool found in untreated samples. Furthermore, $L^{*}$ could also be used as the utmost example to show how much $\mathrm{Cu}$-complexes are resistant to strong and fast oxidization. Note that the extent to which RSS were removed is unknown for both sets, but the shape of voltammograms clearly show that these compounds still have an influence on $\mathrm{Cu}$ - 
657

658

659

660

661

662

663

664

665

666

667

668

669

670

671

672

673

674

675

676

677

678

679

680

speciation, in accordance with the known stability of $\mathrm{Cu}$-sulfides complexes in oxic conditions ${ }^{[82,83]}$. In deep waters, the mixture of $\mathrm{Cu}$-binding ligands including organosulfur compounds and stabilized sulfides which results from the progressive mixing with seawater, is therefore able to cope with the rapid mixing between hydrothermal fluid and seawater which could enable dissolved $\mathrm{Cu}$ to be transported far from the venting source.

\section{Conclusion}

We assessed the apparent speciation of $\mathrm{Cu}$ in the early mixing with seawater of two different black smokers at the Lucky Strike hydrothermal vent field (Mid-Atlantic Ridge). The $\mathrm{Cu}$ binding ligand concentrations were increasing with the $\mathrm{dMn}$ concentrations suggesting a hydrothermal origin of the $\mathrm{Cu}$-ligands detected. For the first time, the apparent $\mathrm{L}$ concentrations were discussed in line with the in situ concentrations of free inorganic sulfides. In the early mixing, it appeared that $\mathrm{L}$ concentrations were following the trend of $\Sigma \mathrm{S}$ when plotting both parameters against $\mathrm{dMn}$. The corresponding stability constants of $\mathrm{Cu}$-ligands (log $\mathrm{K}_{\mathrm{CuL}}^{\prime}$; avg. 12.9) were similar to those already reported for strong organic ligands (e.g. thiols, $\log \mathrm{K}_{\mathrm{CuL}}^{\prime}$ $\sim 13$ ) in deep sea hydrothermal vents ${ }^{[10]}$ but also to that of inorganic sulfide complexes (log $\mathrm{K}_{\mathrm{CuHS}}^{\prime}{ }^{[50]}$. Taking into account the experimental conditions used in the present work, the apparent copper binding capacity measured in all samples was likely a combination of strong organosulfur complexes and stable inorganic $\mathrm{Cu}$-sulfide complexes, able to resist to the progressive oxidization of samples. However, the inorganic sulfides, present at massive concentrations in situ, are probably the major ligand involved in the stabilization of hydrothermally sourced copper in this area, as suggested in earlier work ${ }^{[8,9]}$. Based on the work of Al-Farawati and van den Berg ${ }^{[50]}$ and on sulfides concentrations greater than $100 \mu \mathrm{M}$ in most of our samples, we inferred that $\mathrm{Cu}$ bindings ligands could be predominantly inorganic 
681 sulfur species in the early mixing. This does not invalidate the previous finding on organic

682 copper complexation in hydrothermal vents. The assumption made here is rather that the impact

683 of the organosulfur ligands on $\mathrm{Cu}$-stabilization should be much lower than the one of inorganic

684 sulfides in the buoyant plume because of their low concentration in comparison to sulfides.

685 However, with the aging of the plume, the progressive oxidization of free sulfides and some

686 local mixing with biologically rich diffuse vents, the part of organic ligand should increase, as

687 well as its role on Cu-stabilization. Organosulfur compounds and stabilized sulfides might

688 therefore coexist in the buoyant and neutrally buoyant plume, until the complete oxidation of

689 inorganic sulfides complexes. Finally, our results indicate that this mixture partly resists to

690 strong oxidizing conditions (air-purging) suggesting that copper could be transported far from

691 the vent sources.

692

693

\section{Acknowlegdements}

695

696

697

698

699

700

701

702

703

704

We wish to thank the captains and crew of the two R/V Pourquoi Pas? and Atalante. We are grateful to the Victor 6000 ROV pilots for their assistance at sea, Mathilde Cannat and Jérôme Blandin coordinators of the projects and cruises, Nicolas Gayet for his help in collecting the samples, Céline Liorzou and Marie-Laure Rouget (PSO) for the ICP-AES and ICP-MS measurements. We would like to thank Irena Ciglenečki-Jušić and Zdeslav Zovko for DOC measurements. This work was funded by grants from Ifremer and Université de Bretagne Occidentale (DEI). We acknowledge financial support from the French ANR Luckyscales project (ANR-14-CE02-0008-02) and the EU project EMSO (http://www.emso-eu.org/) (PhD grant to L. Cotte). This work was also supported by the MEBTRACE project granted by the Croatian Science Foundation (IP-2014-09-7530; PI: DO). Finally, we are grateful to two 
705 anonymous reviewers and the editor Peter Croot for their helpful and constructive comments.

706 The authors declare no conflicts of interest.

707 
[1] K. Hirose, Chemical speciation of trace metals in seawater: a review, Analytical Sciences 2006, 22, 1055-1063.

[2] J.C. Alt, Subseafloor processes in Mid-Ocean Ridge hydrothermal systems, Seafloor Hydrothermal Systems: Physical, Chemical, Biological, and Geological Interactions, Geophysical Monograph Series 1995, 91, 85-114.

[3] J.L. Charlou, J.P. Donval, E. Douville, P. Jean-Baptiste, J. Radford-Knoery, Y. Fouquet, A. Dapoigny, M. Stievenard, Compared geochemical signatures and the evolution of Menez Gwen $\left(37^{\circ} 50^{\prime} \mathrm{N}\right)$ and Lucky Strike $\left(37^{\circ} 17^{\prime} \mathrm{N}\right)$ hydrothermal fluids, south of the Azores Triple Junction on the Mid-Atlantic Ridge, Chemical Geology 2000, 171, 49-75. doi:10.1016/S0009-2541(00)00244-8.

[4] E.P. Reeves, J.M. McDermott, J.S. Seewald, The origin of methanethiol in midocean ridge hydrothermal fluids, Proceedings of the National Academy of Sciences 2014, 111, 54745479.

[5] T.M. McCollom, J.S. Seewald, C.R. German, Investigation of extractable organic compounds in deep-sea hydrothermal vent fluids along the Mid-Atlantic Ridge, Geochimica et Cosmochimica Acta 2015, 156, 122-144. doi:10.1016/j.gca.2015.02.022.

[6] V. Klevenz, W. Bach, K. Schmidt, M. Hentscher, A. Koschinsky, S. Petersen, Geochemistry of vent fluid particles formed during initial hydrothermal fluid-seawater mixing along the Mid-Atlantic Ridge, Geochemistry, Geophysics, Geosystems 2011, 12, 1-23. doi:10.1029/2011GC003704.

[7] J.M. Edmond, C. Measures, R.E. McDuff, L.H. Chan, R. Collier, B. Grant, L.I. Gordon, J.B. Corliss, Ridge crest hydrothermal activity and the balances of the major and minor elements in the ocean: The Galapagos data, Earth and Planetary Science Letters 1979, 46, 1-18. doi:10.1016/0012-821X(79)90061-X.

[8] G.W. Luther, T.F. Rozan, M. Taillefert, D.B. Nuzzio, C. Di Meo, T.M. Shank, R.A. Lutz, S.C. Cary, Chemical speciation drives hydrothermal vent ecology, Nature 2001, 410, 813816. doi:10.1038/35071069.

[9] V.P. Edgcomb, S.J. Molyneaux, M.A. Saito, K. Lloyd, S. Böer, C.O. Wirsen, M.S. Atkins, A. Teske, Sulfide ameliorates metal toxicity for deep-sea hydrothermal vent archaea, Applied and Environmental Microbiology 2004, 70, 2551-2555.

[10] S.G. Sander, A. Koschinsky, G. Massoth, M. Stott, K.A. Hunter, Organic complexation of copper in deep-sea hydrothermal vent systems, Environmental Chemistry 2007, 4, 8189.

[11] Z.D. Powell, Voltammetric studies on the stabilisation of dissolved copper in hydrothermal vent fluids, $P h D$ Thesis, University of Otago, Dunedin, New Zealand 2014.

[12] C. Kleint, S. Kuzmanovski, Z. Powell, S.I. Bühring, S.G. Sander, A. Koschinsky, Organic $\mathrm{Cu}$-complexation at the shallow marine hydrothermal vent fields off the coast of Milos (Greece), Dominica (Lesser Antilles) and the Bay of Plenty (New Zealand), Marine Chemistry 2015, 173, 244-252. doi:10.1016/j.marchem.2014.10.012.

[13] S.G. Sander, A. Koschinsky, Metal flux from hydrothermal vents increased by organic complexation, Nature Geoscience 2011, 4, 145-150. doi:10.1038/ngeo1088.

[14] S.A. Bennett, E.P. Achterberg, D.P. Connelly, P.J. Statham, G.R. Fones, C.R. German, The distribution and stabilisation of dissolved $\mathrm{Fe}$ in deep-sea hydrothermal plumes, Earth and Planetary Science Letters 2008, 270, 157-167. doi:10.1016/j.epsl.2008.01.048. 
[15] J.A. Hawkes, D.P. Connelly, M. Gledhill, E.P. Achterberg, The stabilisation and transportation of dissolved iron from high temperature hydrothermal vent systems, Earth and Planetary Science Letters 2013, 375, 280-290. doi:10.1016/j.eps1.2013.05.047.

[16] C. Kleint, J.A. Hawkes, S.G. Sander, A. Koschinsky, Voltammetric investigation of hydrothermal iron speciation, Frontiers in Marine Science 2016, 3, 75. doi:10.3389/fmars.2016.00075.

[17] H. Whitby, C.M.G. van den Berg, Evidence for copper-binding humic substances in seawater, Marine Chemistry 2015, 173, 282-290. doi:10.1016/j.marchem.2014.09.011.

[18] C.R. DeMets, R.G. Gordon, D.F. Argus, S. Stein, Current plate motions, Geophysical Journal International 1990, 101, 425-478.

[19] M. Cannat, A. Briais, C. Deplus, J. Escartín, J. Georgen, J. Lin, S. Mercouriev, C. Meyzen, M. Muller, G. Pouliquen, A. Rabain, P. da Silva, Mid-Atlantic Ridge-Azores hotspot interactions: along-axis migration of a hotspot-derived event of enhanced magmatism 10 to $4 \mathrm{Ma}$ ago, Earth and Planetary Science Letters 1999, 173, 257-269.

[20] S.E. Humphris, D.J. Fornari, D.S. Scheirer, C.R. German, L.M. Parson, Geotectonic setting of hydrothermal activity on the summit of Lucky Strike Seamount ( $37^{\circ} 17^{\prime} \mathrm{N}$, MidAtlantic Ridge), Geochemistry, Geophysics, Geosystems 2002, 3, 1-24.

[21] Y. Fouquet, H. Ondréas, J.L. Charlou, J.P. Donval, J. Radford-Knoery, I. Costa, N. Lourenco, M.K. Tivey, Atlantic lava lakes and hot vents, Nature 1995, 377, 201-201. doi:10.1038/377201a0.

[22] H. Ondréas, M. Cannat, Y. Fouquet, A. Normand, P.M. Sarradin, J. Sarrazin, Recent volcanic events and the distribution of hydrothermal venting at the Lucky Strike hydrothermal field, Mid-Atlantic Ridge, Geochemistry, Geophysics, Geosystems 2009, 10, 1-18. doi:10.1029/2008GC002171.

[23] T. Barreyre, J. Escartín, R. Garcia, M. Cannat, E. Mittelstaedt, R. Prados, Structure, temporal evolution, and heat flux estimates from the Lucky Strike deep-sea hydrothermal field derived from seafloor image mosaics, Geochemistry, Geophysics, Geosystems 2012, 13, 1-29. doi:10.1029/2011GC003990.

[24] P.M. Sarradin, Sarrazin, J., Allais, A. G., Almeida, D., B. V., Boetius, A., Buffier, E., Coiras, E., Colaco, A., Cormack, A., Dentrecolas, S., Desbruyeres, D., Dorval, P., du Buf, H., Dupont, J., Godfroy, A., Gouillou, M., Gronemann, J., Hamel, G., Hamon, M., Hoge, U., Lane, D., Le Gall, C., Leroux, D., Legrand, J., Leon, P., Leveque, J. P., Masson, M., Olu, K., Pascoal, A., Sauter, E., Sanfilippo, L., Savino, E., Sebastiao, L., Santos, R. S., Shillito, B., Simeoni, P., Schultz, A., Sudreau, J. P., Taylor, P., Vuillemin, R., Waldmann, C., Wenzhöfer, F., Zal, F., EXtreme ecosystem studies in the deep OCEan: Technological developments, Ieee 2007, 1-3.

[25] R. Vuillemin, D. Le Roux, P. Dorval, K. Bucas, J.P. Sudreau, M. Hamon, C. Le Gall, P.M. Sarradin, CHEMINI: A new in situ CHEmical MINIaturized analyzer, Deep Sea Research I 2009, 56, 1391-1399. doi:10.1016/j.dsr.2009.02.002.

[26] N. Le Bris, P.M. Sarradin, D. Birot, A.M. Alayse-Danet, A new chemical analyzer for in situ measurement of nitrate and total sulfide over hydrothermal vent biological communities, Marine Chemistry 2000, 72, 1-15. doi:10.1016/S0304-4203(00)00057-8.

[27] K.N. Buck, J. Moffett, K.A. Barbeau, R.M. Bundy, Y. Kondo, J. Wu, The organic complexation of iron and copper: An intercomparison of competitive ligand exchangeadsorptive cathodic stripping voltammetry (CLE-ACSV) techniques, Limnology and Oceanography: Methods 2012, 10, 496-515. doi:10.4319/lom.2012.10.496.

[28] M.L.A.M. Campos, C.M.G. van den Berg, Determination of copper complexation in sea water by cathodic stripping voltammetry and ligand competition with salicylaldoxime, Analytica Chimica Acta 1994, 284, 481-496. doi:10.1016/0003-2670(94)85055-0. 
[29] C. Garnier, I. Pižeta, S. Mounier, J.Y. Benaïm, M. Branica, Influence of the type of titration and of data treatment methods on metal complexing parameters determination of single and multi-ligand systems measured by stripping voltammetry, Analytica Chimica Acta 2004, 505, 263-275. doi:10.1016/j.aca.2003.10.066.

[30] D. Omanović, C. Garnier, I. Pižeta, ProMCC: An all-in-one tool for trace metal complexation studies, Marine Chemistry 2015, 173, 25-39. doi:10.1016/j.marchem.2014.10.011.

[31] I. Pižeta, S.G. Sander, R.J.M. Hudson, D. Omanović, O. Baars, K.A. Barbeau, K.N. Buck, R.M. Bundy, G. Carrasco, P.L. Croot, C. Garnier, L.J.A. Gerringa, M. Gledhill, K. Hirose, Y. Kondo, L.M. Laglera, J. Nuester, M.J.A. Rijkenberg, S. Takeda, B.S. Twining, M. Wells, Interpretation of complexometric titration data: An intercomparison of methods for estimating models of trace metal complexation by natural organic ligands, Marine Chemistry 2015, 173, 3-24. doi:10.1016/j.marchem.2015.03.006.

[32] D. Omanović, M. Branica, Automation of voltammetric measurements by polarographic analyser PAR 384B., Croatica Chemica Acta 1998, 71, 421-433.

[33] I. Pižeta, D. Omanović, M. Branica, The influence of data treatment on the interpretation of experimental results in voltammetry, Analytica Chimica Acta 1999, 401, 163-172. doi:10.1016/S0003-2670(99)00491-2.

[34] D. Omanović, C. Garnier, Y. Louis, V. Lenoble, S. Mounier, I. Pižeta, Significance of data treatment and experimental setup on the determination of copper complexing parameters by anodic stripping voltammetry, Analytica Chimica Acta 2010, 664, 136-143. doi:10.1016/j.aca.2010.02.008.

[35] I. Ciglenečki, D. Krznarić, G.R. Helz, Voltammetry of copper sulfide particles and nanoparticles: Investigation of the cluster hypothesis, Environmental Science \& Technology 2005, 39, 7492-7498. doi:10.1021/es050586v.

[36] D. Krznarić, G.R. Helz, I. Ciglenečki, Prospect of determining copper sulfide nanoparticles by voltammetry: A potential artifact in supersaturated solutions, Journal of Electroanalytical Chemistry 2006, 590, 207-214. doi:10.1016/j.jelechem.2006.03.046.

[37] D. Krznarić, G.R. Helz, E. Bura-Nakić, D. Jurašin, Accumulation mechanism for metal chalcogenide nanoparticles at $\mathrm{Hg}^{0}$ electrodes: Copper sulfide example, Analytical Chemistry 2008, 80, 742-749. doi:10.1021/ac071180z.

[38] D. Omanović, Z. Kwokal, A. Goodwin, A. Lawrence, C.E. Banks, R.G. Compton, S. Komorsky-Lovrić, Trace metal detection in Sibenik Bay, Croatia: Cadmium, lead and copper with anodic stripping voltammetry and manganese via sonoelectrochemistry. A case study, Journal of the Iranian Chemical Society 2006, 3, 128-139. doi:10.1007/BF03245940.

[39] Y. Louis, P. Cmuk, D. Omanović, C. Garnier, V. Lenoble, S. Mounier, I. Pižeta, Speciation of trace metals in natural waters: The influence of an adsorbed layer of natural organic matter (NOM) on voltammetric behaviour of copper, Analytica Chimica Acta 2008, 606, 37-44. doi:10.1016/j.aca.2007.11.011.

[40] L. Cotte, M. Waeles, B. Pernet-Coudrier, P.M. Sarradin, C. Cathalot, R.D. Riso, A comparison of in situ vs. ex situ filtration methods on the assessment of dissolved and particulate metals at hydrothermal vents, Deep Sea Research I 2015, 105, 186-194. doi:http://dx.doi.org/10.1016/j.dsr.2015.09.005.

[41] S.L. Simpson, S.C. Apte, G.E. Batley, Sample storage artifacts affecting the measurement of dissolved copper in sulfidic waters, Analytical Chemistry 1998, 70, 4202-4205. doi:10.1021/ac980006v.

[42] R. Benner, M. Strom, A critical evaluation of the analytical blank associated with DOC measurements by high-temperature catalytic oxidation, Marine Chemistry 1993, 41, 153160. doi:10.1016/0304-4203(93)90113-3. 
[43] J.P. Cowen, G.J. Massoth, R.A. Feely, Scavenging rates of dissolved manganese in a hydrothermal vent plume, Deep Sea Research A 1990, 37, 1619-1637. doi:10.1016/01980149(90)90065-4.

[44] M.P. Field, R.M. Sherrell, Dissolved and particulate Fe in a hydrothermal plume at $9^{\circ} 45^{\prime} \mathrm{N}$, East Pacific Rise: Slow Fe (II) oxidation kinetics in Pacific plumes, Geochimica et Cosmochimica Acta 2000, 64, 619-628. doi:10.1016/S0016-7037(99)00333-6.

[45] P.A. Yeats, J.A. Dalziel, S.B. Moran, A comparison of dissolved and particulate Mn and Al distributions in the Western North-Atlantic, Oceanologica Acta 1992, 15, 609-619.

[46] P.J.M. Buckley, C.M.G. van den Berg, Copper complexation profiles in the Atlantic Ocean: A comparative study using electrochemical and ion exchange techniques, Marine Chemistry 1986, 19, 281-296. doi:10.1016/0304-4203(86)90028-9.

[47] J.E. Jacquot, J.W. Moffett, Copper distribution and speciation across the International GEOTRACES Section GA03, Deep Sea Research II 2015, 116, 187-207. doi:10.1016/j.dsr2.2014.11.013.

[48] M. Waeles, L. Cotte, B. Pernet-Coudrier, V. Chavagnac, C. Cathalot, T. Leleu, A. LaësHuon, A. Perhirin, R.D. Riso, P.-M. Sarradin, On the early fate of hydrothermal iron at deep-sea vents: A reassessment after in-situ filtration, Geophysical Research Letters 2017, 1-8. doi:10.1002/2017GL073315.

[49] I. Ciglenečki, B. Ćosović, Electrochemical study of sulfur species in seawater and marine phytoplankton cultures, Marine Chemistry 1996, 52, 87-97. doi:10.1016/03044203(95)00080-1.

[50] R. Al-Farawati, C.M.G. van den Berg, Metal-sulfide complexation in seawater, Marine Chemistry 1999, 63, 331-352. doi:10.1016/S0304-4203(98)00056-5.

[51] I. Ciglenečki, B. Ćosović, Electrochemical determination of thiosulfate in seawater in the presence of elemental sulfur and sulfide, Electroanalysis 1997, 9, 775-780. doi:10.1002/elan.1140091009.

[52] F. Wang, A. Tessier, J. Buffle, Voltammetric determination of elemental sulfur in pore waters, Limnology and Oceanography 1998, 43, 1353-1361.

[53] I. Ciglenečki, E. Bura-Nakić, M. Marguš, Zinc sulfide surface formation on Hg electrode during cyclic voltammetric scan: an implication for previous and future research studies on metal sulfide systems, Journal of Solid State Electrochemistry 2012, 16, 2041-2046. doi:10.1007/s10008-011-1612-4.

[54] I. Ciglenečki, M. Marguš, E. Bura-Nakić, I. Milanović, Electroanalytical methods in characterization of sulfur species in aqueous environment, Journal of Electrochemical Science and Engineering 2014, 4, 155-163.

[55] I. Milanović, D. Krznarić, E. Bura-Nakić, I. Ciglenečki, Deposition and dissolution of metal sulfide layers at the $\mathrm{Hg}$ electrode surface in seawater electrolyte conditions, Environmental Chemistry 2013, 11, 167-172.

[56] T.F. Rozan, S.M. Theberge, G. Luther, Quantifying elemental sulfur $\left(\mathrm{S}^{0}\right)$, bisulfide $\left(\mathrm{HS}^{-}\right)$ and polysulfides $\left(\mathrm{S}_{\mathrm{x}}{ }^{2-}\right)$ using a voltammetric method, Analytica Chimica Acta 2000, 415, 175-184. doi:10.1016/S0003-2670(00)00844-8.

[57] E. Bura-Nakić, D. Krznarić, D. Jurašin, G.R. Helz, I. Ciglenečki, Voltammetric characterization of metal sulfide particles and nanoparticles in model solutions and natural waters, Analytica Chimica Acta 2007, 594, 44-51. doi:10.1016/j.aca.2007.04.065.

[58] E. Bura-Nakić, D. Krznarić, G.R. Helz, I. Ciglenečki, Characterization of iron sulfide species in model solutions by cyclic voltammetry. Revisiting an old problem, Electroanalysis 2011, 23, 1376-1382. doi:10.1002/elan.201000675.

[59] R. Al-Farawati, C.M.G. van den Berg, The determination of sulfide in seawater by flowanalysis with voltammetric detection, Marine Chemistry 1997, 57, 277-286. doi:10.1016/S0304-4203(97)00014-5. 
[60] L.M. Laglera, C.M.G. van den Berg, Copper complexation by thiol compounds in estuarine waters, Marine Chemistry 2003, 82, 71-89. doi:10.1016/S0304-4203(03)000537.

[61] A. Gartman, M. Yücel, A.S. Madison, D.W. Chu, S. Ma, C.P. Janzen, E.L. Becker, R.A. Beinart, P.R. Girguis, G.W. Luther, Sulfide oxidation across diffuse flow zones of hydrothermal vents, Aquatic Geochemistry 2011, 17, 583-601. doi:10.1007/s10498-0119136-1.

[62] V. Klevenz, S.G. Sander, M. Perner, A. Koschinsky, Amelioration of free copper by hydrothermal vent microbes as a response to high copper concentrations, Chemistry and Ecology 2012, 28, 405-420. doi:10.1080/02757540.2012.666531.

[63] A.G. González, N. Pérez-Almeida, J. Magdalena Santana-Casiano, F.J. Millero, M. González-Dávila, Redox interactions of $\mathrm{Fe}$ and $\mathrm{Cu}$ in seawater, Marine Chemistry 2016, 179, 12-22. doi:10.1016/j.marchem.2016.01.004.

[64] M.F.C. Leal, C.M.G. van den Berg, Evidence for strong copper(I) complexation by organic ligands in seawater, Aquatic Geochemistry 1998, 4, 49-75. doi:10.1023/A:1009653002399.

[65] M.J. Walsh, B.A. Ahner, Determination of stability constants of $\mathrm{Cu}(\mathrm{I}), \mathrm{Cd}(\mathrm{II}) \& \mathrm{Zn}(\mathrm{II})$ complexes with thiols using fluorescent probes, Journal of Inorganic Biochemistry 2013, 128, 112-123. doi:10.1016/j.jinorgbio.2013.07.012.

[66] N. Pérez-Almeida, M. González-Dávila, J. Magdalena Santana-Casiano, A.G. González, M. Suárez de Tangil, Oxidation of $\mathrm{Cu}(\mathrm{I})$ in seawater at low oxygen concentrations, Environmental Science \& Technology 2013, 47, 1239-1247. doi:10.1021/es302465d.

[67] D.A. Hansell, Recalcitrant dissolved organic carbon fractions, Annual Review of Marine Science 2013, 5, 421-445.

[68] L. Guo, P.H. Santschi, K.W. Warnken, Dynamics of dissolved organic carbon (DOC) in oceanic environments, Limnology and Oceanography 1995, 40, 1392-1403. doi:10.4319/lo.1995.40.8.1392.

[69] D.A. Hansell, C.A. Carlson, Deep-ocean gradients in the concentration of dissolved organic carbon, Nature 1998, 395, 263-266. doi:10.1038/26200.

[70] S.Q. Lang, D.A. Butterfield, M.D. Lilley, H. Paul Johnson, J.I. Hedges, Dissolved organic carbon in ridge-axis and ridge-flank hydrothermal systems, Geochimica et Cosmochimica Acta 2006, 70, 3830-3842. doi:10.1016/j.gca.2006.04.031.

[71] J.A. Hawkes, P.E. Rossel, A. Stubbins, D. Butterfield, D.P. Connelly, E.P. Achterberg, A. Koschinsky, V. Chavagnac, C.T. Hansen, W. Bach, T. Dittmar, Efficient removal of recalcitrant deep-ocean dissolved organic matter during hydrothermal circulation, Nature Geoscience 2015, 8, 856-860.

[72] S.A. Bennett, P.J. Statham, D.R.H. Green, N. Le Bris, J.M. McDermott, F. Prado, O.J. Rouxel, K. Von Damm, C.R. German, Dissolved and particulate organic carbon in hydrothermal plumes from the East Pacific Rise, $9^{\circ} 50$ 'N, Deep Sea Research I 2011, 58, 922-931. doi:10.1016/j.dsr.2011.06.010.

[73] J.A. Hawkes, C.T. Hansen, T. Goldhammer, W. Bach, T. Dittmar, Molecular alteration of marine dissolved organic matter under experimental hydrothermal conditions, Geochimica et Cosmochimica Acta 2016, 175, 68-85. doi:10.1016/j.gca.2015.11.025.

[74] C. Konn, J.L. Charlou, N.G. Holm, O. Mousis, The production of methane, hydrogen, and organic compounds in ultramafic-hosted hydrothermal vents of the Mid-Atlantic Ridge, Astrobiology 2015, 15, 381-399.

[75] M.D. Schulte, K.L. Rogers, Thiols in hydrothermal solution: standard partial molal properties and their role in the organic geochemistry of hydrothermal environments, Geochimica et Cosmochimica Acta 2004, 68, 1087-1097. doi:10.1016/j.gca.2003.06.001. 
[76] J.L. Charlou, J.P. Donval, C. Konn, H. Ondréas, Y. Fouquet, P. Jean-Baptiste, E. Fourré, High production and fluxes of $\mathrm{H}_{2}$ and $\mathrm{CH}_{4}$ and evidence of abiotic hydrocarbon synthesis by serpentinization in ultramafic-hosted hydrothermal systems on the Mid-Atlantic Ridge, Diversity of Hydrothermal Systems on Slow Spreading Ocean Ridges, Geophysical Monograph Series 2010, 188, 265-296.

[77] M. Bailly-Bechet, M. Kerszberg, F. Gaill, F. Pradillon, A modeling approach of the influence of local hydrodynamic conditions on larval dispersal at hydrothermal vents, Journal of Theoretical Biology 2008, 255, 320-331. doi:10.1016/j.jtbi.2008.08.016.

[78] M.C. Lohan, D.W. Crawford, D.A. Purdie, P.J. Statham, Iron and zinc enrichments in the northeastern subarctic Pacific: Ligand production and zinc availability in response to phytoplankton growth, Limnology and Oceanography 2005, 50, 1427-1437.

[79] B.W. Mountain, T.M. Seward, Hydrosulfide/sulfide complexes of copper(I): Experimental confirmation of the stoechiometry and stability of $\mathrm{Cu}(\mathrm{HS})_{2}{ }^{-}$to elevated temperatures, Geochimica et Cosmochimica Acta 2003, 67, 3005-3014. doi:10.1016/S0016-7037(03)00303-X.

[80] J.Z. Zhang, F.J. Millero, Investigation of metal sulfide complexes in sea water using cathodic stripping square wave voltammetry, Analytica Chimica Acta 1994, 284, 497504. doi:10.1016/0003-2670(94)85056-9.

[81] E. Mittelstaedt, J. Escartín, N. Gracias, J.A. Olive, T. Barreyre, A. Davaille, M. Cannat, R. Garcia, Quantifying diffuse and discrete venting at the Tour Eiffel vent site, Lucky Strike hydrothermal field, Geochemistry, Geophysics, Geosystems 2012, 13, 1-18. doi:10.1029/2011GC003991.

[82] T.F. Rozan, G. Benoit, G.W. Luther, Measuring metal sulfide complexes in oxic river waters with square wave voltammetry, Environmental Science \& Technology 1999, 33, 3021-3026. doi:10.1021/es981206r.

[83] P.J. Superville, I. Pižeta, D. Omanović, G. Billon, Identification and on-line monitoring of reduced sulphur species (RSS) by voltammetry in oxic waters, Talanta 2013, 112, 5562. 
983

984

985

986

\begin{tabular}{cccccccc}
\hline Site & Sample & $\mathrm{T}_{\text {PEPITO }}$ & $\mathrm{pH}$ & $\mathrm{dMn}$ & $\mathrm{dCu}$ & $\mathrm{L}$ & $\operatorname{logK}_{\mathrm{CuL}}^{\prime}$ \\
\hline & & ${ }^{\circ} \mathrm{C}$ & & $\mu \mathrm{M}$ & $\mathrm{nM}$ & $\mathrm{nM}$ & \\
\hline & 02598 A1 & 5.27 & 7.5 & 1.08 & 12 & - & - \\
& 02598 A3 & 17.2 & 6.1 & 11.1 & 129 & - & - \\
& 02598 B1 & 31.1 & 5.6 & 19.9 & 771 & $2104 \pm 126$ & $12.86 \pm 0.15$ \\
& 02598 B3 & 47.0 & 5.1 & 23.6 & 32 & $230 \pm 12$ & $13.03 \pm 0.07$ \\
& 02598 C1 & 57.0 & 5.3 & 37.2 & 39 & $377 \pm 15$ & $12.68 \pm 0.05$ \\
& 02598 C2 & 72.6 & 5.2 & 48.8 & 212 & $746 \pm 30$ & $13.38 \pm 0.07$ \\
Aisics & 02598 C3 & 67.6 & 5.2 & 44.9 & 119 & $1059 \pm 74$ & $12.95 \pm 0.10$ \\
& 02598 D1 & 55.0 & 5.3 & 39.4 & 26 & $351 \pm 23$ & $12.95 \pm 0.08$ \\
& $02598 \mathrm{D} 2$ & 96.7 & 5.0 & 64.3 & 63 & $768 \pm 88$ & $12.91 \pm 0.17$ \\
& $02598 \mathrm{D} 3$ & 108 & 4.9 & 72.9 & 456 & $2972 \pm 156$ & $12.97 \pm 0.08$ \\
& $02598 \mathrm{E} 1$ & 121 & 4.9 & 83.4 & 50 & $336 \pm 25$ & $12.37 \pm 0.07$ \\
& $02598 \mathrm{E} 3$ & 154 & 4.7 & 102 & 312 & $742 \pm 89$ & $12.99 \pm 0.20$ \\
\hline & $10606 \mathrm{~A} 1$ & 4.97 & 7.4 & 0.65 & 13 & $32.5 \pm 2.6$ & $12.55 \pm 0.09$ \\
& $10606 \mathrm{~A} 2$ & 10.0 & 6.7 & 4.26 & 32 & $61.5 \pm 5.5$ & $12.96 \pm 0.14$ \\
& $10606 \mathrm{~A} 3$ & 20.3 & 6.2 & 11.8 & 76 & $175 \pm 12$ & $12.89 \pm 0.08$ \\
& $10606 \mathrm{~B} 2$ & 35.4 & 5.8 & 26.9 & 365 & $519 \pm 20$ & $13.15 \pm 0.09$ \\
& $10606 \mathrm{~B} 3$ & 50.3 & 5.6 & 36.2 & 234 & $294 \pm 46$ & $12.69 \pm 0.32$ \\
& $10606 \mathrm{C} 1$ & 60.1 & 5.5 & 44.4 & 102 & $499 \pm 25$ & $12.57 \pm 0.05$ \\
& $10606 \mathrm{C} 2$ & 68.8 & 5.5 & 47.9 & 409 & $740 \pm 37$ & $12.95 \pm 0.10$ \\
& $10606 \mathrm{C} 3$ & 80.4 & 5.4 & 70.8 & 325 & $585 \pm 35$ & $12.98 \pm 0.10$ \\
& $10606 \mathrm{D} 1$ & 88.8 & 5.3 & 65.2 & 335 & $1024 \pm 33$ & $13.13 \pm 0.05$ \\
\hline
\end{tabular}

988

989

990

991

992

Table 1. Calculated complexing parameters for $\mathrm{Cu}\left(\mathrm{L}\right.$ and $\left.\mathrm{K}{ }^{\prime} \mathrm{CuL}\right)$ obtained in untreated samples (2015) from Aisics and Y3 hydrothermal vents (Lucky Strike, MAR). Mean temperature (recorded during sampling) as well as natural $\mathrm{pH}$, total dissolved manganese $(\mathrm{dMn})$ and total dissolved copper $(\mathrm{dCu})$ concentrations measured are also provided.

Table 2. Calculated complexing parameters for $\mathrm{Cu}\left(\mathrm{L}^{*}\right.$ and $\left.\mathrm{K}^{\prime}{ }_{\mathrm{CuL}}\right)$ and dissolved $\mathrm{Cu}$ concentrations $\left(\mathrm{dCu}^{*}\right)$ obtained in pretreated (air purged-filtered) samples from Aisics hydrothermal vent (2016). Mean temperature (recorded during sampling) as well as natural $\mathrm{pH}$, total dissolved manganese ( $\mathrm{dMn})$, total dissolved copper $(\mathrm{dCu})$ and DOC concentrations obtained before any pretreatment of these samples are also provided.

\begin{tabular}{cccccccccc}
\hline Site & Sample & $\mathrm{T}_{\text {PEPITO }}$ & $\mathrm{pH}$ & $\mathrm{dMn}$ & $\mathrm{dCu}$ & $\mathrm{dCu}^{*}$ & $\mathrm{DOC}$ & $\mathrm{L}^{*}$ & $\operatorname{logK}^{\prime *} \mathrm{CuL}$ \\
\hline \multirow{6}{*}{ Aisics } & ${ }^{\circ} \mathrm{C}$ & & $\mu \mathrm{M}$ & $\mathrm{nM}$ & $\mathrm{nM}$ & $\mu \mathrm{M}$ & $\mathrm{nM}$ & \\
& 09632 A1 & 5.40 & 7.5 & 1.90 & - & 2.5 & 55.5 & - & - \\
& $09632 \mathrm{~A} 2$ & 12.7 & 5.8 & 5.03 & 7 & 3.6 & 55.6 & - & - \\
& $09632 \mathrm{~A} 3$ & 19.1 & 5.4 & 9.85 & 121 & 3.5 & 49.3 & - & - \\
& $09632 \mathrm{~B} 1$ & 32.2 & 5.1 & 14.0 & 277 & 10 & 59.1 & $22.8 \pm 1.2$ & $13.04 \pm 0.05$ \\
& 09632 B2 & 56.4 & 5.4 & 42.5 & 55 & 14 & 51.2 & $26.9 \pm 7.5$ & $12.75 \pm 0.32$ \\
& 09632 B3 & 73.6 & 5.2 & 38.4 & 410 & - & - & - & - \\
& $09632 \mathrm{C} 1$ & 87.5 & 4.6 & 68.8 & - & 6.2 & 24.8 & $18.2 \pm 1.0$ & $12.61 \pm 0.05$ \\
& $09632 \mathrm{C} 2$ & 114 & 4.7 & 77.5 & - & 6.3 & 40.8 & $41.8 \pm 2.9$ & $12.57 \pm 0.06$ \\
& $09632 \mathrm{C} 3$ & 126 & 4.6 & 70.9 & 42 & 3.1 & 89.8 & $43.9 \pm 5.1$ & $12.96 \pm 0.10$ \\
\hline
\end{tabular}


994 Table 3. Concentrations of $\Sigma \mathrm{S}\left(\mathrm{H}_{2} \mathrm{~S}, \mathrm{HS}^{-}, \mathrm{S}^{2-}\right)$ and $\mathrm{O}_{2}$ obtained with in situ instruments at Aisics and 995 Y3 hydrothermal vents. In order to plot all in situ parameters as a function of $\mathrm{dMn}$, the corresponding 996 manganese concentrations $\left(\mathrm{dMn}_{\Sigma \mathrm{S}}\right)$ were estimated from $\mathrm{T}_{\mathrm{CHEMINI}}$ thanks to the linear $\mathrm{dMn}-\mathrm{T}_{\text {PEPITO }}$ 997 relationship obtained at Aisics and Y3 (see SI).

\begin{tabular}{|c|c|c|c|c|c|}
\hline Site and date & Sample & $\mathrm{T}_{\text {CHEMINI}(\Sigma \mathrm{S})}$ & $\mathrm{dMn}_{\Sigma \mathrm{S}}$ & $\Sigma \mathrm{S}$ & $\mathrm{O}_{2}$ \\
\hline & & ${ }^{\circ} \mathrm{C}$ & $\mu \mathrm{M}$ & $\mu \mathrm{M}$ & $\mu \mathrm{M}$ \\
\hline \multirow{12}{*}{$\begin{array}{c}\text { Aisics } \\
(02598-2015)\end{array}$} & $02598 \mathrm{~A} 1$ & 5.18 & 0.83 & 0.98 & 276 \\
\hline & 02598 A3 & 17.2 & 11.1 & 27.7 & 230 \\
\hline & 02598 B1 & 31.1 & 19.9 & 62.6 & 243 \\
\hline & 02598 B3 & 47.0 & 23.6 & 138 & 210 \\
\hline & $02598 \mathrm{C} 1$ & 57.0 & 37.2 & 321 & 190 \\
\hline & $02598 \mathrm{C} 2$ & 72.6 & 48.8 & 265 & 215 \\
\hline & $02598 \mathrm{C} 3$ & 67.6 & 44.9 & 237 & 189 \\
\hline & $02598 \mathrm{D} 1$ & 55.0 & 39.4 & 250 & 219 \\
\hline & $02598 \mathrm{D} 2$ & 96.7 & 64.3 & 231 & 186 \\
\hline & 02598 D3 & 108 & 72.9 & 191 & 143 \\
\hline & $02598 \mathrm{E} 1$ & 121 & 83.4 & 169 & 162 \\
\hline & 02598 E3 & 154 & 102 & 187 & 146 \\
\hline \multirow{9}{*}{$\begin{array}{c}\text { Aisics } \\
(09632-2016)\end{array}$} & 09632 A1 & 7.98 & 2.71 & 5.25 & - \\
\hline & 09632 A2 & 11.4 & 5.03 & 89.0 & - \\
\hline & 09632 A3 & 19.5 & 10.6 & 160 & - \\
\hline & 09632 B1 & 30.3 & 17.9 & 224 & - \\
\hline & 09632 B2 & 54.1 & 34.1 & 263 & - \\
\hline & 09632 B3 & 60.0 & 38.1 & 286 & - \\
\hline & $09632 \mathrm{C} 1$ & 108 & 70.7 & 320 & - \\
\hline & 09632 C2 & 117 & 76.6 & 335 & - \\
\hline & $09632 \mathrm{C} 3$ & 120 & 78.9 & 352 & - \\
\hline \multirow{8}{*}{$\begin{array}{c}\text { Y3 } \\
(07582-2014)\end{array}$} & $07582 \mathrm{~A} 1$ & 5.98 & 1.47 & 77.7 & - \\
\hline & 07582 A2 & 9.90 & 4.37 & 52.2 & - \\
\hline & 07582 A3 & 23.4 & 14.4 & 132 & - \\
\hline & 07582 B1 & 45.1 & 30.4 & 275 & - \\
\hline & 07582 B2 & 54.7 & 37.5 & 286 & - \\
\hline & 07582 B3 & 78.2 & 55.0 & 363 & - \\
\hline & $07582 \mathrm{C} 1$ & 97.5 & 69.3 & 415 & - \\
\hline & $07582 \mathrm{C} 2$ & 70.8 & 49.5 & 266 & - \\
\hline \multirow{9}{*}{$\begin{array}{c}\text { Y3 } \\
(10606-2015)\end{array}$} & $10606 \mathrm{~A} 1$ & - & - & - & 247 \\
\hline & 10606 A2 & - & - & - & - \\
\hline & 10606 A3 & - & - & - & 264 \\
\hline & 10606 B2 & - & - & - & 249 \\
\hline & 10606 B3 & - & - & - & 240 \\
\hline & $10606 \mathrm{C} 1$ & - & - & - & 209 \\
\hline & $10606 \mathrm{C} 2$ & - & - & - & 242 \\
\hline & $10606 \mathrm{C} 3$ & - & - & - & 183 \\
\hline & 10606 D1 & - & - & - & 183 \\
\hline
\end{tabular}



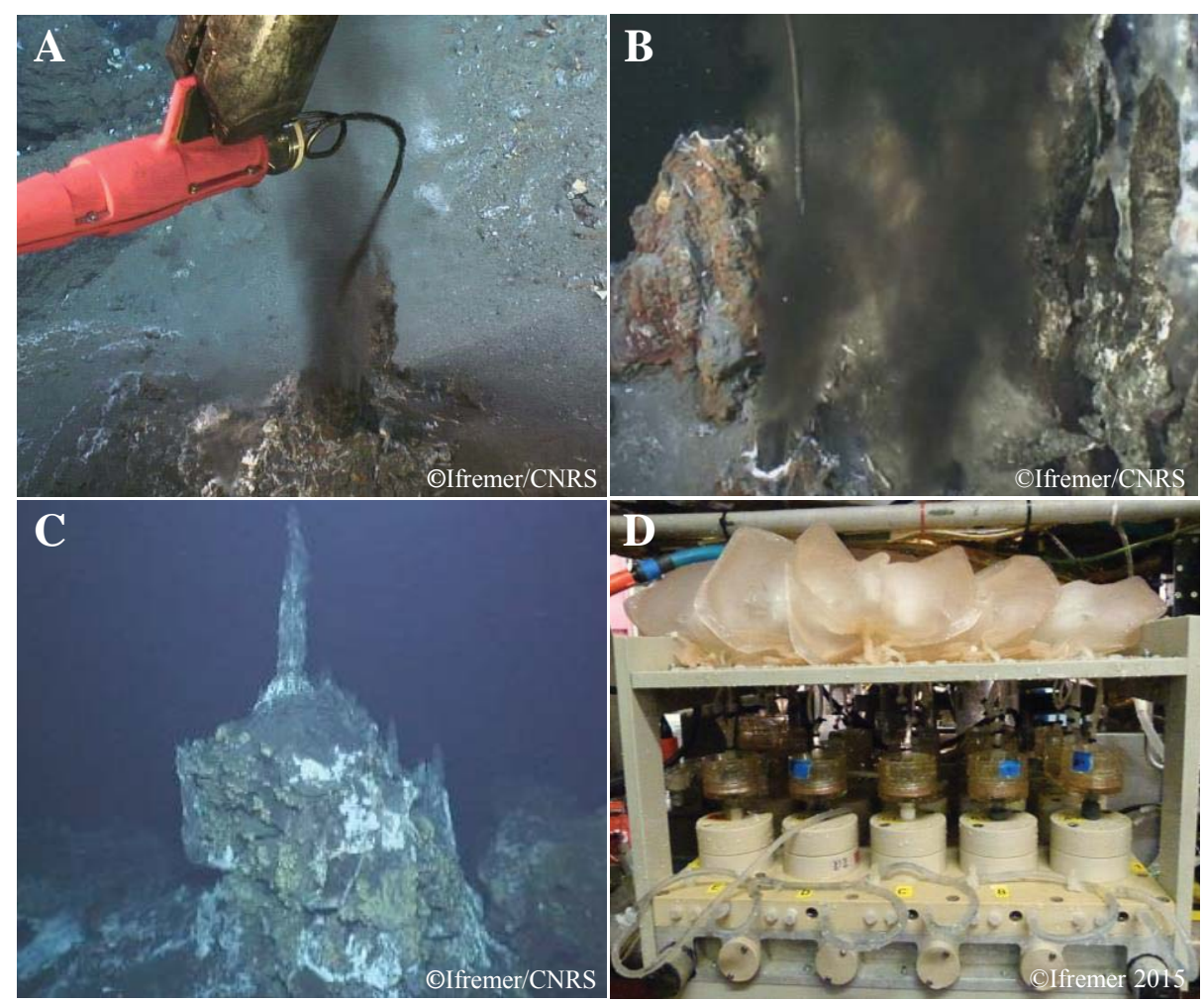

1000 Figure 1. (A) Main black smoker Aisics (Endmember temperature: $307^{\circ} \mathrm{C}$ ) at the Lucky strike vent field (MAR) sampled during the Momarsat 2015 and 2016 cruises using the PEPITO sampler. The titaniumSilicon inlet coupled to the ROV temperature probe is also shown. (B) Main black smoker Y3 (Endmember temperature: $326^{\circ} \mathrm{C}$ ) during sampling. (C) Overall view of the site Y3, Lucky Strike (MAR). (D) PEPITO sampler implemented on the ROV with freshly collected samples filtered in-situ. The reader might see that 2 PVC-bags were attached to each filter holder: 2 bags for each sample were thus collected in 2015 . After recovery, one bag was frozen at $-20^{\circ} \mathrm{C}$ whereas the other one was poisoned with $\mathrm{NaN}_{3}$ and stored at $4^{\circ} \mathrm{C}$ with the aim to compare the impact of sample storage on $\mathrm{Cu}$ speciation. As freezing was suspected to worsen the aggregation of colloidal phases, only poisoned bags were analyzed at that moment. Samples collected in 2016 were treated the same way, as indicated in the text. 


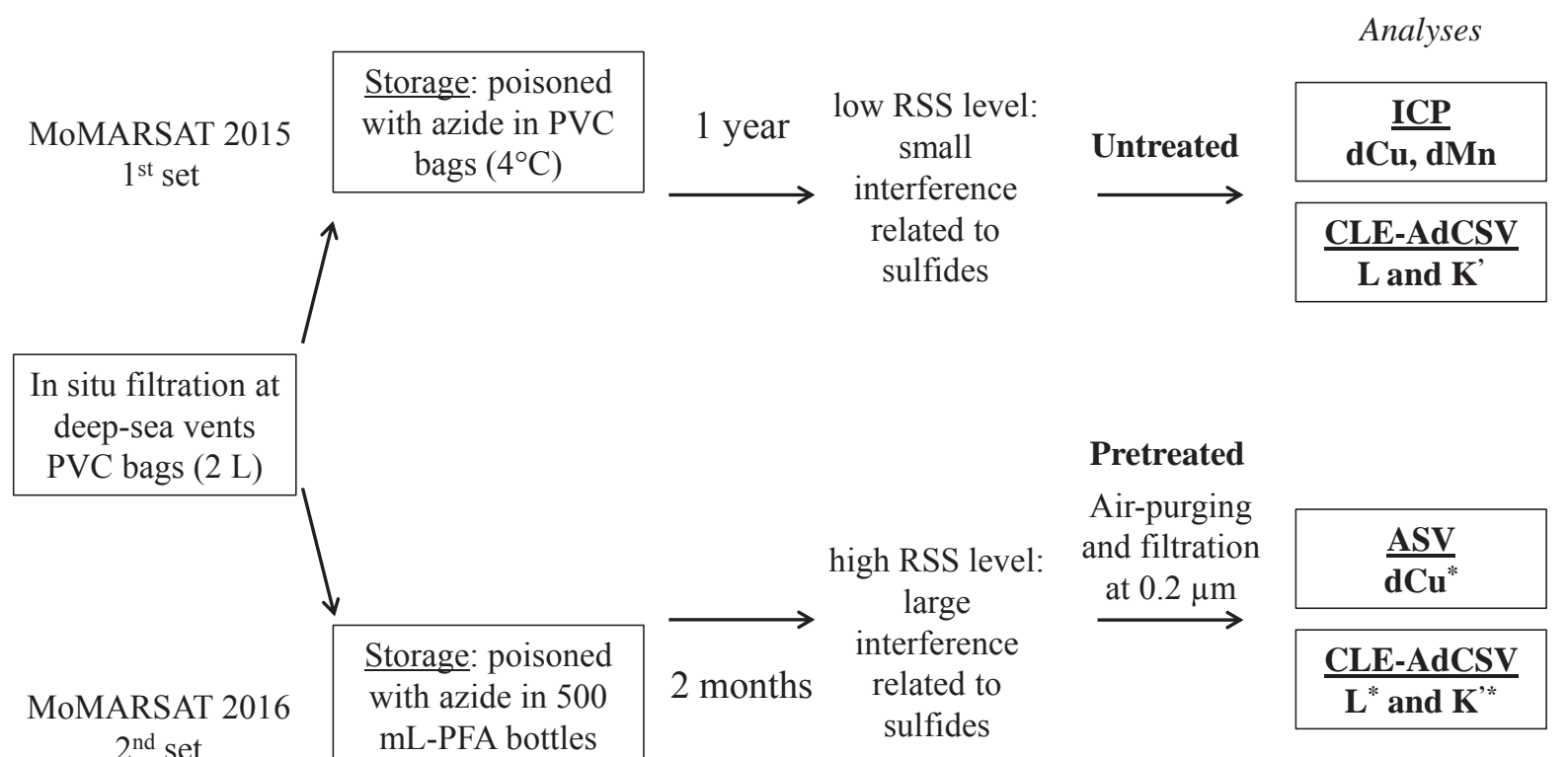

1012 Figure 2. Summary diagram of the strategy used from the storage to the analyses for the assessment of dissolved copper $(\mathrm{dCu})$ before being pretreated (see paragraph 2.5). RSS denote Reduced sulfide species.

1016 

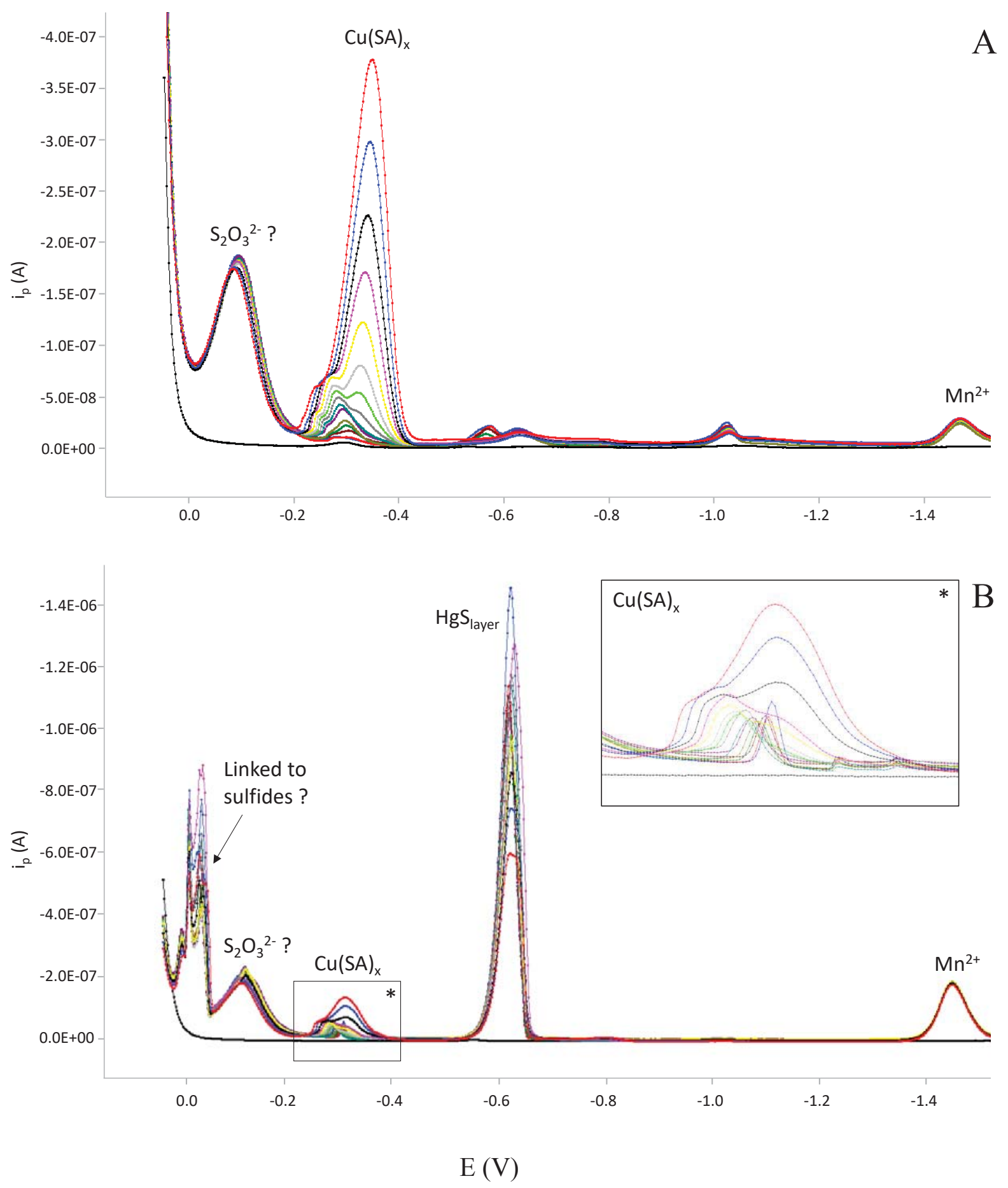

1019 Figure 3. A) Typical voltammogram obtained for complexometric titrations in the untreated samples 1020 (1st set; e.g. 02598 C1). Untreated samples were 10-fold diluted in UVSW. B) Typical voltammogram obtained for the pretreated samples (e.g. $09632 \mathrm{C} 3$ ). The right panel shows all $\mathrm{Cu}(\mathrm{SA})_{\mathrm{x}}$ signals for the whole titration experiment. The detailed scale of potential in the inset is provided in Figure S3. All titration experiments were performed after overnight equilibration at $\mathrm{pH} \sim 8.2$ and $4 \mu \mathrm{M}$ SA. Black signals correspond to the blank (UVSW). The $\mathrm{Cu}(\mathrm{SA})_{\mathrm{x}}$ signal was extracted from the interfering signals (i.e. 'shoulders' at $-0.27 \mathrm{~V}$ vs $\mathrm{Ag} / \mathrm{AgCl}$ ) observed at low additions of $\mathrm{Cu}$ for both sets of samples. 


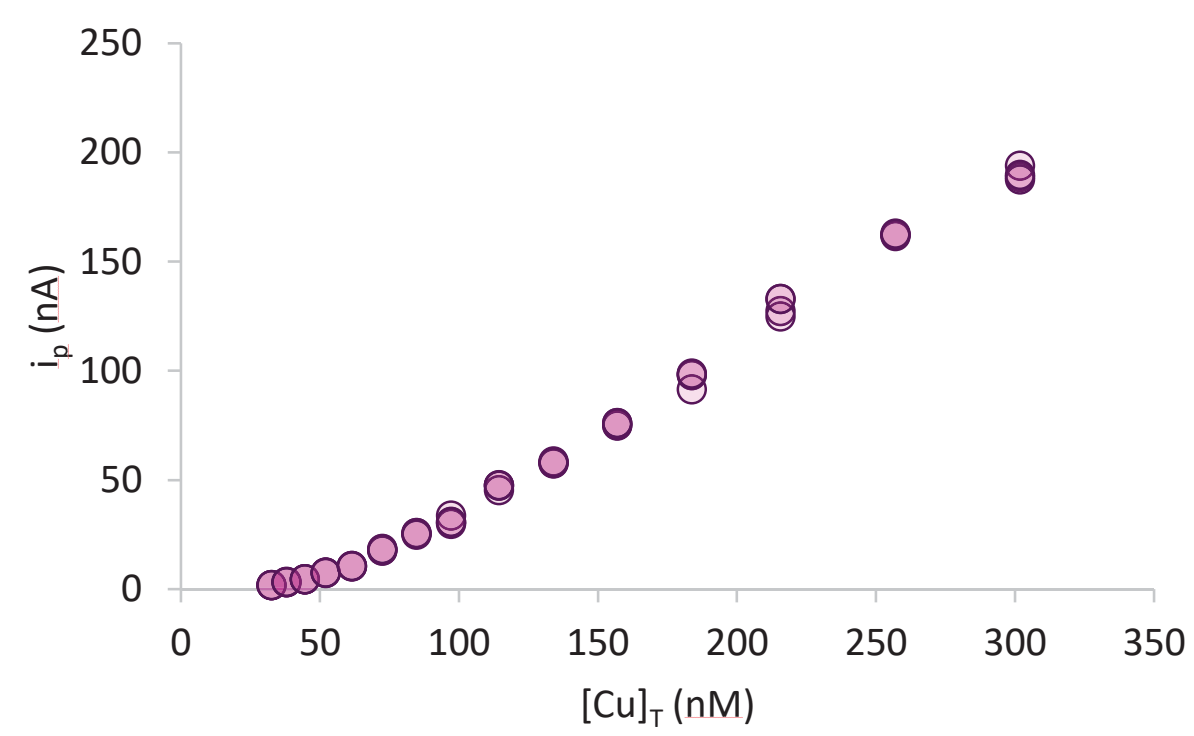

1028

1029 Figure 4. Typical titration curve obtained after voltammogram treatment and signal extraction (e.g. $103010606 \mathrm{C} 3,2015)$ with $14 \mathrm{Cu}$-standard additions (5 or 4 replicates), $4 \mu \mathrm{M}$ of SA, $0.01 \mathrm{M}$ borate buffer $1031 \quad(\mathrm{pH} \sim 8.2)$.

1032

1033

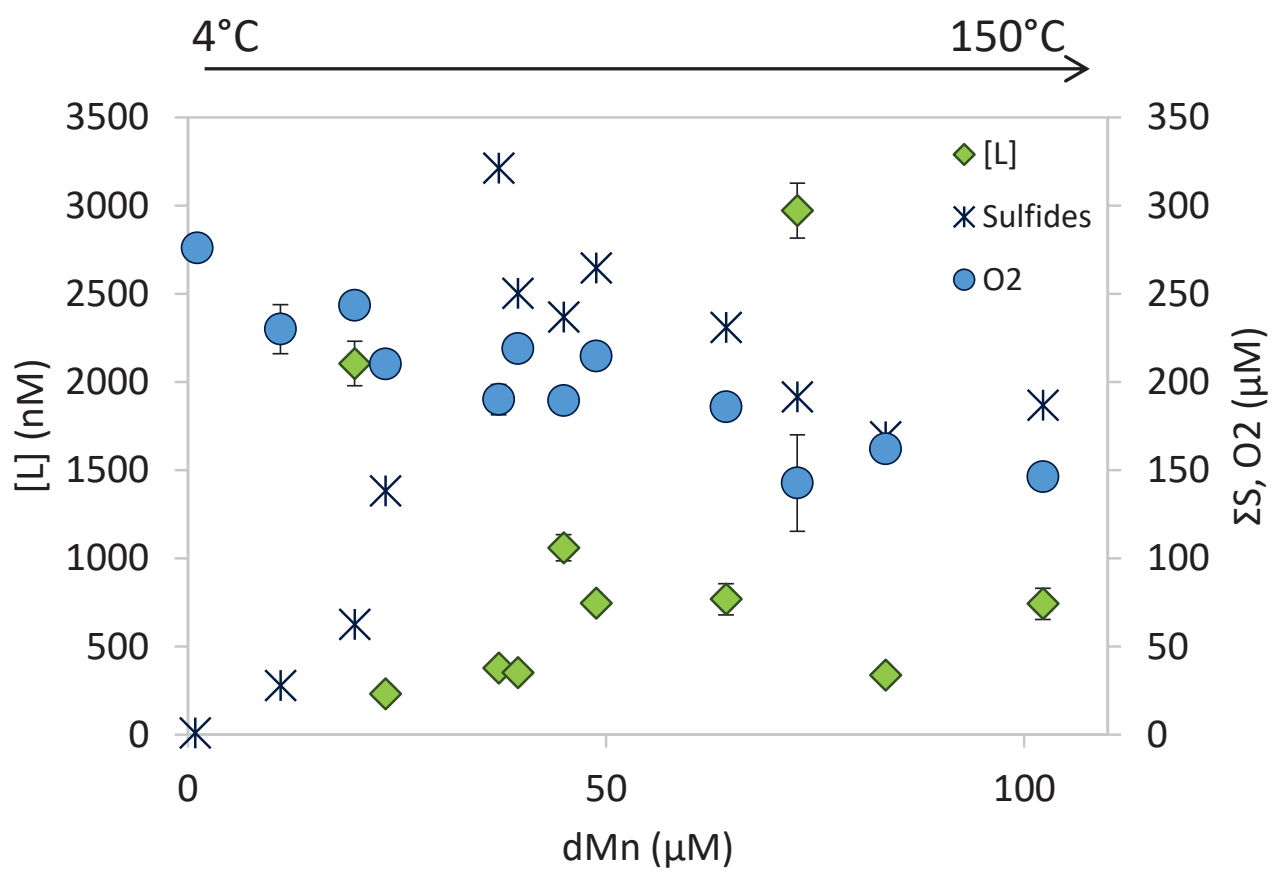

Figure 5. Concentrations of Cu-binding ligands and in-situ concentrations of free sulfides $\left(\Sigma \mathrm{S}=\mathrm{H}_{2} \mathrm{~S}+\right.$ $\mathrm{HS}^{-}+\mathrm{S}^{2-}$ ) measured with the CHEMINI analyzer at the main smoker of Aisics in 2015 (dive 02598). Blue dots refer to the in-situ concentrations of dissolved oxygen $\left(\mathrm{O}_{2}\right)$ measured by the Optode (Aanderaa). The linear relationship between temperature and $\mathrm{dMn}$ is $\mathrm{T}\left({ }^{\circ} \mathrm{C}\right)=1.43(\mathrm{dMn})+4 ; \mathrm{r}^{2}=0.99$ (Figure S4), where the intercept refers to the deep seawater temperature. Errors bars for [L] are summarized in Table 1. 


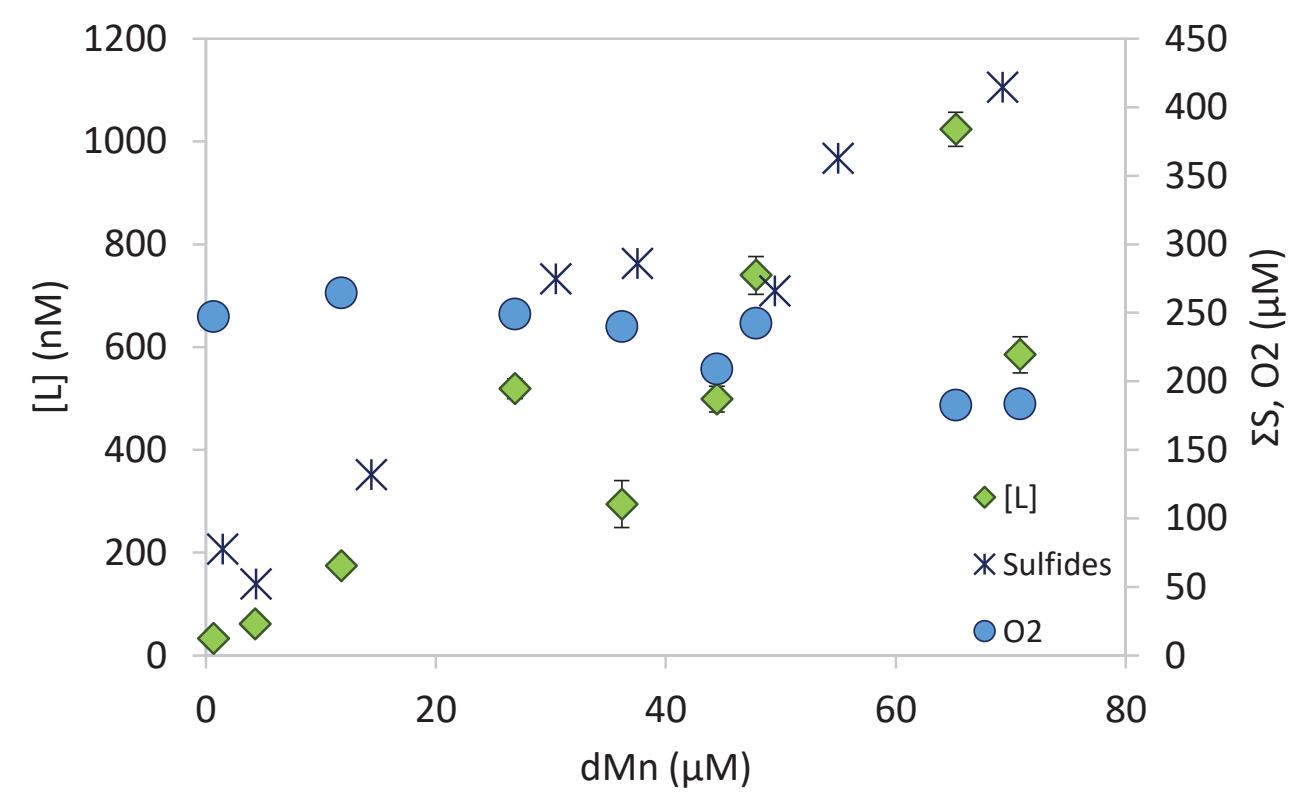

1043 Figure 6. Concentrations of $\mathrm{Cu}$-binding ligands ([L], dive 10606) and in-situ concentrations of free 1044 sulfides $\left(\Sigma \mathrm{S}=\mathrm{H}_{2} \mathrm{~S}+\mathrm{HS}^{-}+\mathrm{S}^{2-}\right)$ measured with the CHEMINI analyzer at the main smoker of Y3 in 1045 2014. The linear relationship between temperature and $\mathrm{dMn}$ is $\mathrm{T}\left({ }^{\circ} \mathrm{C}\right)=1.35(\mathrm{dMn})+4 ; \mathrm{r}^{2}=0.99$ (Figure 1046 S5).

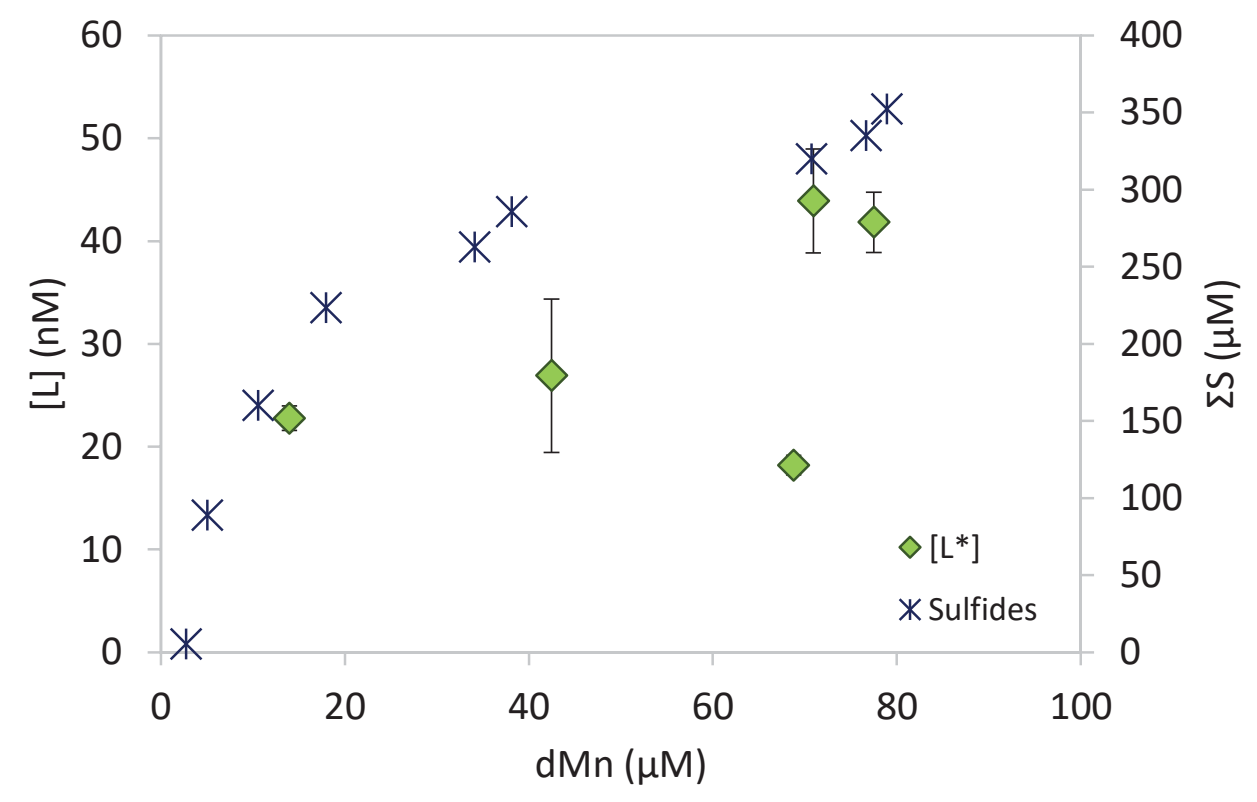

1049 Figure 7. Concentrations of Cu-ligands and in-situ concentrations of free sulfides $\left(\Sigma \mathrm{S}=\mathrm{H}_{2} \mathrm{~S}+\mathrm{HS}^{-}+\mathrm{S}^{2}\right)$ 1050 measured with the CHEMINI analyzer at the main smoker of Aisics in 2016. $\Sigma \mathrm{S}$ can be plotted as a 1051 function of dMn thanks to the linear relationship $\mathrm{T}\left({ }^{\circ} \mathrm{C}\right)=1.47(\mathrm{dMn})+4 ; \mathrm{r}^{2}=0.94$ (Figure $\mathrm{S} 6$ ). 